NBER WORKING PAPER SERIES

\title{
ASYMMETRIC INFORMATION AND REMITTANCES: EVIDENCE FROM MATCHED ADMINISTRATIVE DATA
}

\author{
Thomas Joseph \\ Yaw Nyarko \\ Shing-Yi Wang \\ Working Paper 20986 \\ http://www.nber.org/papers/w20986 \\ NATIONAL BUREAU OF ECONOMIC RESEARCH \\ 1050 Massachusetts Avenue \\ Cambridge, MA 02138 \\ February 2015
}

We are extremely grateful to the teams at UAE Exchange and the UAE Ministry of Labor for their assistance in accessing the data sets and for answering our questions. This paper has benefited from conversations with or comments from Santosh Anagol, Rachel Heath, Rob Jensen, Melanie Khamis, Adriana Kugler, Annemie Maertens, Laura Schechter, Mark Rosenzweig, Dean Yang and various seminar participants. Afshan Aman, Victor Archavski, Patrick Dejearnette and Minkwang Jang provided excellent research assistance. The authors acknowledge financial support from the New York University in Abu Dhabi Research Institute, and the Center for Technology and Economic Development. The views expressed herein are those of the authors and do not necessarily reflect the views of the National Bureau of Economic Research.

At least one co-author has disclosed a financial relationship of potential relevance for this research. Further information is available online at http://www.nber.org/papers/w20986.ack

NBER working papers are circulated for discussion and comment purposes. They have not been peerreviewed or been subject to the review by the NBER Board of Directors that accompanies official NBER publications.

(C) 2015 by Thomas Joseph, Yaw Nyarko, and Shing-Yi Wang. All rights reserved. Short sections of text, not to exceed two paragraphs, may be quoted without explicit permission provided that full credit, including $(\odot$ notice, is given to the source. 
Asymmetric Information and Remittances: Evidence from Matched Administrative Data

Thomas Joseph, Yaw Nyarko, and Shing-Yi Wang

NBER Working Paper No. 20986

February 2015

JEL No. F22,F24,J60,O15,O53

\begin{abstract}
$\underline{\text { ABSTRACT }}$
Using new data matching remittances and monthly payroll disbursals, we demonstrate how fluctuations in migrants' earnings in the United Arab Emirates affect their remittances. We consider three types of income fluctuations that are observable by families at home: seasonalities, weather shocks and a labor reform. Remittances move with all of these income changes. Remittances do not move with an individual's growth in earnings over time. The slope of the relationship between earnings and time in the UAE varies across individuals and is not easy to observe by families. Thus, a key characteristic that drives remittance behavior is the observability of income rather than other features of these fluctuations. The results are consistent with a private information model where remittances are viewed by the migrant worker as payments to their families in an income-sharing contract.
\end{abstract}

Thomas Joseph

IIM Udaipur

India

thomas.joseph@iimu.ac.in

Yaw Nyarko

Department of Economics

New York University

19 W. 4th Street, 6th Floor

New York, NY 10012

yaw.nyarko@nyu.edu
Shing-Yi Wang

The Wharton School

University of Pennsylvania

3620 Locust Walk

Philadelphia, PA 19104

and NBER

was@wharton.upenn.edu 


\section{Introduction}

The number of international migrants has been growing over time. Estimates from the United Nations suggest that the number has increased from 154 million in 1990 to over 230 million in 2013 (UN News 2013). The majority of international migrants originate from developing countries, and remittances to developing countries, valued at $\$ 325$ billion in 2009 , has exceeded foreign development aid and is approaching the magnitudes of foreign direct investment. International remittances may play an important role in the economic growth of poor countries. At a micro level, temporary migrants remit a substantial portion of their income to their families at home, and remittances have been shown to improve the economic outcomes of receiving households (Yang and Martinez 2005, Yang 2008).

While migrants make substantial financial transfers to their families at home, the geographic separation inherent in international migration corresponds with substantial information asymmetries in the economic choices and outcomes of both sides. ${ }^{1}$ Theoretical models of intra-household resource allocation emphasize the potential for different preferences among household members but have generally assumed perfect information (Chiappori 1988, Manser and Brown 1980, McElroy and Horney 1981, Lundberg and Pollack 1993). However, an emerging empirical literature suggests that asymmetric information within households over assets and income can affect the allocation of resources. Our paper contributes to the new literature that emphasizes the importance of asymmetric information in intrahousehold outcomes. Using new high frequency data on earnings and remittances of migrants, we examine whether private information that migrants have about their own earnings fluctuations affects their remittance patterns.

The prior empirical literature on asymmetric information and household behavior falls into two categories: laboratory experiments and field experiments. In a laboratory setting bringing in husbands and wives, Ashraf (2009) shows that Filipino men deposit the experimental transfer to their own accounts when that decision is private and commit to consumption when the decision is public. Ambler (2014) shows that Salvadorian migrants in Washington, DC remit a smaller share of a windfall given in the lab experiment when the total amount of the windfall is not revealed to the recipient. In a lab experiment in Kenya, Jakiela and Ozier (2012) find that women are willing to reduce their expected earnings to keep their income hidden from relatives. In addition to the lab experiments, there is one related field experiment on asymmetric information. Goldberg (2010) runs public and private lotteries

\footnotetext{
${ }^{1}$ Seshan and Zubrickas (2014) interview both male migrants and their wives at home and find evidence that husbands working in Qatar underreport their earnings by about $20 \%$ to their wives at home in India. De Weerdt, Genicot and Mesnard (2014) find substantial information asymmetries over assets in family networks and that the discrepancies are positively correlated with physical distance.
} 
and finds that winners of public lotteries spend $35 \%$ more than winners of private lotteries in the period immediately after the lottery.

The experimental settings offer the ability to cleanly manipulate the flow of information to household members. However, the evidence that exploits randomized variation in information generated in lab settings and in field experiments is limited to looking at small, one-time windfalls. One key contribution of our study is that we examine real-world variation in earned income. This distinction may be important as standard models of consumption smoothing suggest that individuals should respond differently to income fluctuations that are anticipated versus unanticipated and those that are permanent versus transitory. ${ }^{2}$ By moving beyond windfalls, our paper contributes to our understanding of whether models of private information are relevant in explaining how remittances respond to variation in earned income. Also, because we exploit several income fluctuations that exhibit different characteristics, we can separate out whether the other characteristics of income fluctuations (transitory versus permanent and anticipated versus unanticipated) matter in addition to the observability of income (public versus private). ${ }^{3}$

We are able to take a new approach to examining motivations to remit because we have access to a unique data set that offers high frequency records that include millions of remittance transactions of migrants in the United Arab Emirates (UAE). Our main data are administrative records from a financial firm in the UAE that offers remittance services to individuals and payroll processing services to firms. We are able to match the remittance transactions data with administrative data on monthly earnings disbursals for hundreds of thousands of migrant workers from 2009 to 2012. To our knowledge, this is the only high frequency analysis of the relationship between earnings and remittances. Furthermore, our analysis may be subject to less measurement error and recall bias than other studies because we exploit records of actual remittance transactions and payroll payments rather than survey data. This is potentially quite important; as Kapur and Akee (2012) document using two independent sources of data on remittances into Indian bank accounts, actual remittance deposits are twice the self-reported amounts. ${ }^{4}$

This paper contributes to the growing literature on the economic drivers of the remittance behavior of migrants (Dustmann and Mestres 2010, Lucas and Stark 1985, Rapoport and Docquier 2006, Yang and Choi 2007, Yang 2008, Yang 2011). We develop a new framework of asymmetric informa-

\footnotetext{
${ }^{2}$ A good overview of models of the permanent income hypothesis is presented by Japelli and Pistaferri (2010).

${ }^{3}$ We characterize income fluctuations as public if they are easy to verify or observe by family members at home. This verification may involve asking other individuals working in the UAE about aggregate trends that are experienced by almost all migrants in the UAE.

${ }^{4}$ See also Grigorian, Melkonyan and Shonkwiler (2008).
} 
tion between migrants and their families at home where remittances are treated as a payment on an income-sharing contract that applies to the observable income of migrants. In this model, remittances should move with income differently depending on whether the income fluctuation is observable by the family at home or not. In contrast, the observability of income should not matter under models of pure altruism towards families at home, or in standard exchange models where remittances are used to buy services such as taking care of assets and relatives or repayments of loans that financed migration.

In our empirical work, we begin by documenting whether month-to-month fluctuations in income correspond with changes in remittances. Our results show that overall remittances move positively with fluctuations in an individual's income. If we assume that these month-to-month fluctuations in income are exogenous, then the estimates suggest an income elasticity of remittances of around 0.33. Next, we examine four specific types of income fluctuations that vary in characteristics of ease of observability by family at home, whether they are anticipated or unanticipated and whether they are transitory or permanent. This allows us to determine whether the relationship between remittances and income depends on specific characteristics of the income.

First, we show that remittances move positively with seasonalities in earnings, which are public, anticipated and transitory. We find that Ramadan has a particularly large and negative impact on both earnings and remittances. Next, we examine the impact of weather shocks on earnings and remittances. We examine rainfall and heat shocks, measured as the deviation of precipitation and heat from the mean levels in each city and month, respectively. This follows in a large literature that uses weather shocks as a source of exogenous variation in income (Kazianga and Udry 2006, Jacoby and Skoufias 1998, Paxson 1992, Wolpin 1982). We find that both earnings and remittances fall with this public, unanticipated, transitory shock. To further separate the effects of the attributes of income fluctuations, we use a labor reform that increased the earnings of workers to examine the impact of an unanticipated, permanent shock on the remittance behavior of migrants. Because this is an aggregate shock, we characterize this as public. We find that both income and remittances move positively with this type of income change as well.

There is one type of income fluctuation for which we find that remittances move in an opposite direction from earnings: length of stay in the country. Migrants' earnings increase on average over their time in the UAE, while the average remittances decline. ${ }^{5}$ This does not appear to be driven by selection in the types of individual who choose to stay in or leave the UAE. Rather, the evidence suggests that this pattern is driven by a story of hidden income where the evolution of earnings over

\footnotetext{
${ }^{5}$ Our result that migrants' income increases over their experience in the UAE is consistent with the results in the literature on the assimilation of immigrants (Borjas 1994, LaLonde and Topel 1997).
} 
time may not be fully known by families at home.

We provide evidence to support the idea that the individual gradient between time in the country and earnings is private information. Migrants with identical characteristics upon arrival can experience a positive or negative evolution in their earnings over time in the UAE; employers learn about the ability of workers and pay them differently according to their productivity. We examine two groups of migrants who appear similar at the time of their arrival in the UAE but differ in their subsequent evolution of their earnings over time in the UAE. Workers whose salaries increase over time remit a constant amount (or slightly less) over time. This is consistent with the idea that they hide their additional earnings over time from their families. In contrast, workers whose salaries decrease over time and do not have incentive to hide their long-run earnings trend remit less over time. We also look at variation in the share of co-workers that are from the same home district to examine whether the private information effect is mitigated when there are co-workers who might know and report your earnings status to your family at home.

By exploiting anticipated versus unanticipated and transitory versus permanent income fluctuations, this paper also contributes to the empirical literature that tests models of consumption smoothing (Paxson 1993, Chaudhuri and Paxson 1993, Jacoby and Skoufias 1998, Japelli and Pistaferri 2010, Khandker 2012). The predictions of models of consumption smoothing suggest that individuals are able to adjust saving and smooth consumption differently based on the type of change in income. To our knowledge, we are the first paper to test whether migrants smooth remittances over various types of income fluctuations. Smoothing remittances over anticipated changes to income would suggest that remittances are treated as migrants' own consumption. In contrast, adjusting remittances to transitory shocks but not to permanent ones would suggest remittances are treated by migrants as saving. The separation between whether remittances are saving and investment or current consumption is particularly relevant for the broader question of how remittance flows affect economic growth in developing countries.

\section{Background on Migrants in the UAE}

Following the discovery of oil in the area, the United Arab Emirates was established in 1971 as a federation of seven Emirates: Abu Dhabi, Dubai, Sharjah, Ajman, Umm-al-Quwain, Ras al-Khaimah, al-Fujairah. The subsequent rapid economic growth of the UAE was accompanied by a large inflow of foreign workers. Recent statistics indicate that foreign workers constitute approximately $89 \%$ of the total population and $96 \%$ of the total labor force in the UAE (Forstenlechner and Rutledge 2011). 
Foreign workers enter the UAE on two to three year work visas that are tied with their work contracts with a specific employer. ${ }^{6}$ An employer can fire migrant workers at any time, which corresponds with an almost immediate revocation of the work visa. ${ }^{7}$ Migrant workers can terminate an existing contract with an employer in two ways. First, they can return to their home countries at any time. However, there are stipulations on how long they must stay in the home country (usually six months) before returning to the UAE on a new work visa. Workers who leave before fulfilling a contract must pay for their own airfare home while the cost is borne by the firm if the worker quits at the end of the contract. Second, workers can change to a new employer prior to the end of the contract without leaving the UAE only if they had written approval from their current employer. Prior to 2011, written approval was still needed if a worker wanted to change employers after completing a contract. After 2011, a new labor reform allowed workers the ability to switch employers at the end of their contract without written permission from the initial employer.

Workers enter the UAE on contracts that specify their minimum hours and the accompanying earnings for those hours. Despite these long-term contracts that specify minimum earnings, we demonstrate that most migrants experience substantial month-to-month fluctuations in wages (almost always above the amount stipulated in the contract) that is largely reflective of variation in hours worked, including overtime. Most contracts also include in-kind benefits, such as food and housing in labor camps. Other benefits include employer-provided health insurance, which is mandated by law.

The majority of migrant workers live in dormitory-like housing in labor camps. Given that several migrants share a single room, saving money in their living quarters in order to bring cash or other valuables back physically may not be a very secure option. According to data from the 2011 World Bank Global Findex survey of a randomly selected, nationally representative sample of about 1,000 individuals in the UAE, $78 \%$ did not save in a financial institution in the past 12 months. Given that this sample includes UAE citizens as well as migrants, this is likely to be an overestimate of the number of migrants who use financial institutions in the UAE to store savings. Thus, migrants are unlikely to save the earnings up over time in the UAE to bring cash and valuables physically back with them when they return to their home country either permanently or for a visit.

Migration to the UAE is almost always considered temporary as there is no pathway for foreign workers to attain citizenship following years of legal residence. Furthermore, while foreign women can achieve citizenship through marriage, foreign men cannot and the vast majority of foreign workers are

\footnotetext{
${ }^{6}$ Standard work visas were three years in length prior to 2011 , and two years in length subsequently.

${ }^{7}$ Staying past the expiration of the work visa can lead to imprisonment. However, migrant workers are allowed to appeal unjust treatment by employers, such as withholding wages, in court.
} 
male. ${ }^{8}$ The income requirements for workers to bring their spouses and families prevent most migrant workers from living with their families in the UAE.

It is illegal for firms or recruiting agencies to charge migrant workers fees for receiving a job assignment in the UAE. Recruiting agencies are supposed to receive their commissions only from firms in the UAE. While it is difficult to know the share of workers who pay recruitment fees and the average costs, informal interviews by Human Rights Watch (2009) indicate that almost all construction workers paid manpower firms in their home countries amounts ranging from USD $\$ 1,800$ to USD $\$ 4,100$ for a job assignment.

\section{Conceptual Framework}

This section presents a simple framework where remittances are the result of an income-sharing contract between households and migrants. Migrants have some private information about their income realizations in the host country. The model that we present here will have predictions that are unique from the standard existing models of remittances, including models of altruism and exchange. Appendix Section A adapts and presents simple versions of the models where remittances are motivated primarily by altruism or exchange to demonstrate that the key predictions of the model of asymmetric information cannot be explained by these other models.

\subsection{Remittances as Payments in Income-Sharing Contracts under Asymmetric Information}

Migrants in the host country earn income, $y$, which is comprised of two components, $y_{o}$ and $y_{h}$, that vary in how difficult it is for family members at home to verify. While migrants move to the UAE based on a job offer with an expectation of $y$, the actual income received month-to-month is subject to shocks that can be either positive or negative. Each income component has its own shock over time, denoted by $\mu_{o}$ and $\mu_{h}$. Each of these components of income has its own cost for the family at home to verify, $c_{o}$ and $c_{h}$, where $c_{h}>c_{o} \geq 0$. In other words, it is much more costly to verify fluctuations in the hidden component of income, $y_{h}$, than in the observable component of income, $y_{o}$, and this cost, $c_{h}$, can be infinite (so it can be impossible to verify this type of income).

The migrant promises to remit a fixed proportion, $\tau$, of his income to families at home. Financing international migration can be expensive and remittances may be payments on the contract where

\footnotetext{
${ }^{8}$ Intermarriage with Emirati nationals is legal but not encouraged. The government established the Marriage Fund in 1992, granting 70,000 dirham (19,064 USD) to Emirati couples at the time of marriage with an additional 40,000 dirham $(10,890 \mathrm{USD})$ to the groom if they do not divorce in the first year.
} 
families help finance the costs of migration. Alternatively, $\tau$ may not be part of an explicit contract based on financing migration but a social norm for income sharing. With each remittance transfer sent, the migrant provides a report on his income realization where the claim by the migrant is denoted by $\tilde{y}$. Given their receipt of $\tau \tilde{y}$, households at home can choose whether to incur the costs, $c_{h}$ and $c_{o}$, to verify either of the components of income. If households find that $\tilde{y}<y$, they can inflict a

punishment on the migrant, denoted by $m(y, \tilde{y})$. Punishments may include divorce or eviction from networks at home. Given that there is no path to citizenship for migrants in the UAE, almost all migrants anticipate that they must return to their home countries eventually and may want to have the advantages of their social networks when they return.

The utility of the migrant is increasing in his earnings, $y$, and decreasing in the amount he remits, $\tau \tilde{y}$, the severity of punishment and the probability that his family discovers that $y>\tilde{y}$. Thus, the migrant faces a tradeoff between lying about his income in order to keep more of the income for himself and the risk of being caught lying and punished. The household's utility is increasing in the amount of remittances received, $\tau \tilde{y}$, and makes a decision regarding whether or not to pay the costs for verifying the accuracy of the migrant's income report, $\tilde{y}$.

We do not make additional assumptions on the utility functions of the migrants or the households. It would be possible to directly incorporate other existing models of remittances, including the exchange motive or partial (though not pure) altruism. However, the current framework produces testable implications without further assumptions. The model of asymmetric information implies that remittances should tend to move with a migrant's overall income, y. As shown in Appendix Section A, this prediction is also consistent with the models of altruism and exchange. However, the model of asymmetric information is unique in predicting that whether the income fluctuation is easy for the households at home to observe (or verify) matters for remittances. We should see remittances moving with income fluctuations that are more public or observable. In contrast, remittances may move less or not move at all with positive income changes that can be hidden from the family at home. At the same time, migrants have more incentive to truthfully reveal private information about negative fluctuations in income than about positive fluctuations.

\subsection{Summary of Empirical Predictions}

We examine four types of income fluctuations, three of which are observable by households at home and one that is not. Seasonalities are predictable, observable and transitory. Weather shocks, including rainfall and extreme heat, offer a type of income shock that is unanticipated and transitory. For a 
permanent, unanticipated and observable shock to income, we examine a labor reform that shifted up workers' earnings to a new, higher level. ${ }^{9}$

We consider the idea that the returns to time in the UAE may be a private unanticipated and permanent change to migrants' income in the UAE. Unlike the other income fluctuations, this one varies at the individual level and reflects firm learning about the individual productivity of the worker. Thus, it may be difficult for families at home to know if this gradient is positive, negative or zero for a specific migrant. While some migrants experience a positive permanent change, others experience a negative one. The private information model of remittances suggests that migrants will not reveal positive returns to time to their families at home but do have incentive to share information about the unobserved component of income if they experience negative returns to time in the UAE. Whether the returns to time are positive or negative should only have asymmetric effects under the model where migrants have private information.

Furthermore, we test a prediction of the model that heterogeneity across individuals in the observability of an income fluctuation should matter for remittances. We look at variation across workers in the number of co-workers who are from the same home district or home state. Having more co-workers from the same area may suggest that it is less difficult or costly for the migrant's household to verify how he is performing at a firm over time in the UAE, including whether the worker is promoted or demoted or how many overtime hours a person is working. Co-workers may also be able to provide additional information about how much a person is earning over time by observing their spending patterns in the UAE.

The different income fluctuations allow us to provide evidence in favor of a model of asymmetric information and to reject models of pure altruism or standard exchange models. In contrast to observability, remittances move with income regardless of other characteristics, in particular the predictability and the permanence of the income fluctuation. The results on transitory versus permanent and anticipated versus unanticipated income fluctuations also shed light on a model of altruism with consumption smoothing. If remittances finance the consumption of family members at home and the migrant wants to smooth their consumption, then we would expect remittances to be smoothed over anticipated income fluctuations and move with unanticipated shocks. ${ }^{10}$

\footnotetext{
${ }^{9}$ While we consider this a type of permanent income shock, it can only last as long as workers stay in the UAE and it is important to note that workers cannot stay in the UAE forever. However, workers can continue to re-sign multi-year contracts and remain working in the UAE for decades. The vast majority of workers remain in the UAE after their first multi-year contract expires.

${ }^{10}$ This is discussed in greater detail in Appendix Section A.
} 


\section{Data}

\subsection{Payroll and Remittances Data}

The data are from a financial company based in the UAE whose primary operations involve remittance and foreign exchange services. The firm is a very large player in this market, accounting for the majority of the total remittance flows out of the UAE and approximately $5 \%$ of total global remittance flows in 2010. In addition to funds transfer and exchange, the firm also offers payroll disbursal services in the UAE. Approximately 10-15\% of the migrant labor force receive their earnings from this firm.

We obtained remittances transactions from the firm over the period from January 2009 to October 2012. Transactions can occur at any frequency, but in order to combine the transactions data with the salary, we aggregate transactions to a monthly level. The firm offers many types of transactions for remittances, including Western Union, Xpress Money, Associate Branch Transfer, Demand Draft. These options vary in their speed of delivery and locations for pickup in the home countries. The cost of remittance depends on the type but the cheapest options are about USD $\$ 4.50$ per transaction. Among the months in which remittances are observed to occur through this firm, the median and mode number of remittances transactions for each individual per month is one.

The firm also shared their records on payroll disbursals for the period from January 2009 to October 2012. The entire sample of employees receiving wage payments from the payroll firm include 427,265 unique individuals working in 20,366 firms. In the UAE, salaries are stipulated by law to be paid out on a monthly basis. ${ }^{11}$ There are on average 17.6 monthly salary observations per worker. A key advantage of the data is that they represent the actual income payment transferred to workers. However, the observed earnings may not be representative of total compensation for several reasons. First, workers receive substantial in-kind benefits, including housing and food. This is not a major concern for the analysis in the paper because the value of in-kind benefits is very unlikely to change month-to-month over a worker's contract with an employer; thus, we can remove the impact of in-kind benefits with individual fixed effects. Furthermore, the payments in-kind cannot be transferred abroad by the recipient like earnings can. Second, workers may supplement earnings in their primary jobs with informal work. This is unlikely to be as common in the UAE as in other contexts because it is illegal for migrant workers to receive compensation for work outside of the employer associated with their visas. In addition, migrant workers do not have a lot of free time; we estimate that the migrants in our data are working about 60 hours per week for their employer. ${ }^{12}$

\footnotetext{
${ }^{11}$ Less than $5 \%$ of observations have multiple payments made to an individual in a month. We aggregate those numbers into the total earned in that month.

${ }^{12}$ This estimate is based on the assumption that any earnings received above the contract earnings are the result of
} 
One disadvantage of the data is that the amount of information available for each worker is very limited. The salary disbursal information is connected to an employee data set that contains a few individual characteristics including nationality, age, and gender. We do not observe hours worked in each month so we cannot calculate wage rates. We have no information about marital status or the economic situation of their families at home.

The details on merging the remittance transactions data and the payroll disbursals data are provided in Appendix B. We use two key identifiers to link these two types of data. The first is a customer registration number that can appear in both data sets and is generated by the financial firm. For salary disbursals and transactions that are not linked using the customer registration number, we use another identifier called the labor card id number. This number is provided to migrant workers by the government and is unique to each worker-contract.

\subsection{Ministry of Labor Administrative Data}

In addition to the data set containing administrative records on payroll disbursals and remittance transactions, we also make use of data on migrant workers from the UAE Ministry of Labor (MOL). The MOL data contains detailed information on the terms of the labor contracts signed between migrant workers and firms in the UAE. Thus, we have information on the exact month in which the workers' jobs begin. We use this information to construct the amount of time that the migrant has been in the UAE. The MOL data also has individual characteristics that are not available in the other data set, including religion, education, and the salary and hours terms of the contract.

Another advantage of the MOL data is that it offers an individual identifier, called a person code, that is constant over time in addition to the labor card identifier which changes each time an individual signs a new contract. While the labor card identifier available in the financial transactions data would allow us to link panel observations of individuals within labor contracts, this person code allows us to link the panel observations in the payroll and remittance data across labor contracts. In other words, we use the person identifier to link individuals that sign additional contracts with the same firm after their initial two or three year contract expires and to link individuals who switch firms (if both firms use the the private company providing the data for payroll processing).

We merge together the payroll and remittances data with the data from the Ministry of Labor using the labor card identification number. ${ }^{13}$ We are able to match just over $80 \%$ of the observations in

overtime hours and the legally mandated overtime rate is between 1.25 to 1.5 times the standard hourly wage. This does not include substantial commute times as workers are often transported by bus from labor camps in more remote areas to cities to work.

${ }^{13}$ See Appendix B for more details on matching the Ministry of Labor data to the financial transactions data from the 
the payroll data with the MOL data. ${ }^{14}$ The reason that we are unable to match all of the observations is largely driven by the fact that the MOL does not have jurisdiction over all migrant workers in the UAE. Domestic workers and any workers in free-zone areas of the UAE fall under the jurisdiction of the Ministry of the Interior rather than the Ministry of Labor. Comparing the MOL data that we received to UN population figures for migrant workers in the UAE in 2012 suggests that the MOL data covers approximately $80 \%$ of all migrant workers in the country.

\subsection{Summary Statistics}

Column 1 of Table 1 displays the summary statistics for the full sample of the remittance transactions. The complete remittances sample includes over 34 million individual-month observations. The average amount remitted in a month is 2668 dirham (USD \$726) and India represents the destination for slightly over half of the occurrences of remittances. ${ }^{15}$

Column 2 of Table 1 presents characteristics of the workers for which we have salary data. Workers in this sample earn an average of 1433 dirham (USD \$390) per month. About one-half of the sample reports being of Indian nationality. Over $99 \%$ of the employee sample are male. The average worker is around 35 years old. The data contained written information on workers' occupations, which were coded using the Standard Occupational Classification (SOC) system by at least two research assistants. ${ }^{16}$ We then categorize outdoor occupations as construction, grounds maintenance, and farming. The remainder, including jobs in manufacturing and service, are categorized as indoor occupations. About half of the sample works in jobs that are likely to be outdoors, mainly construction.

Time in the UAE (in months divided by 10) is a time-varying variable, calculated using the first job that the worker had in the UAE based on data from the Ministry of Labor. There are two demographic variables available in the MOL that are not available in the financial firm data. We have information on religion and education for those salary observations that merge successfully with the MOL data. About a third of migrants report being Muslim and about $40 \%$ have high education, which

private firm.

${ }^{14}$ See Appendix Figures A.1 and A.2 in Naidu, Nyarko and Wang (2014) for a comparison of the distribution of types of individuals that merge successfully between the MOL data and the payroll data. The earnings distributions of the unmatched MOL data and the data that matches into the payroll data is extremely similar for the lower end with some differences at the upper end of the earnings distribution suggesting that the payroll data is more oriented towards the median and lower end of the salary distribution of migrants and under-represents migrants at the high end of the earnings distribution.

${ }^{15}$ Nominal earnings and remittances are converted to real terms using the monthly consumer price index published by the UAE National Bureau of Statistics. These numbers are in 2007 dirham.

${ }^{16}$ If the two research assistants coded the written entry differently, we had another round of coding done independently by a third research assistant. In many cases, the written description was empty or too ambiguous to be coded. For example, a job description of "Worker" did not receive an SOC code. We thank Mengxing Lin, Marton Pono, and Cheng $\mathrm{Xu}$ for assistance in this coding. 
we define as higher than intermediate education, which is some secondary school education without having completed the secondary school degree.

Panel D presents the coefficient of variation for earnings and remittances within the duration of a work contract. ${ }^{17}$ The coefficient of variation for monthly earnings disbursed to migrant workers is around 0.3. This indicates a substantial amount of month-to-month variation in earnings on each work contract. Thus, it is not the case that these workers are paid the same amount each month despite being on long-term work contracts. Our conversations with people in the UAE suggest that this variation is at least partially driven by monthly variation in hours worked and includes higher wages for overtime. There is also substantial month-to-month variation in the amount remitted. In fact, the coefficient of variation on remittances is even higher than on earnings. This provides some initial evidence that workers are not smoothing the amount remitted in response to income fluctuations.

The characteristics of individual-months in the sample that are successfully merged with both remittance and earnings information are in column 3 of Table 1 . This is the main sample used in the analysis in the paper. The final merged sample that includes all of the demographic variables in addition to remittances and salaries includes 553,647 observations. The average amount remitted per month in the merged sample is much smaller than the average amount in the full remittances sample. ${ }^{18}$ The average salary in the merged sample is higher than in the full payroll sample by about 120 dirham (33 USD) per month. ${ }^{19}$ The summary statistics suggest that on average migrants are remitting about $85 \%$ of their monthly income. This is reasonable given that food and lodging is provided by employers for many migrant workers. The characteristics of individuals in the merged sample are fairly similar to the full payroll sample along all of the observation characteristics. The merged sample has slightly more outdoor workers and their time in the UAE is slightly lower than in the sample with earnings only.

Analysis with the merged sample of positive observations of both remittances and salary requires the assumption that months in which observations of either salary or remittance information (or both) are missing are similar to observations in which we observe both sets of information. This may be true for several reasons. First, they may be remitting through the company in our data but do not

\footnotetext{
${ }^{17}$ Unlike the other panels of the table, Panel D includes one observation per worker contract.

${ }^{18}$ Panel B of Appendix Figure A.1 shows the kernel densities of log monthly remittances for observations that merge with the salary data as compared with observations that do not merge with the salary data. The figure shows that the unmerged observations tend to be more extreme.

${ }^{19}$ Panel A of Appendix Figure A.1 shows the distribution of log monthly earnings in the merged sample and in the unmerged payroll sample. While the distributions are fairly similar, the sample of merged observations is slightly shifted to the right. This suggests that individuals that use UAExchange for remittances have slightly higher earnings than other individuals employed in firms that use UAExchange for payroll processing.
} 
provide their customer registration number at the time of the transaction. ${ }^{20}$ Many observations of remittances in the data contain neither a customer registration number nor a labor card identification number. Second, it is possible that migrants use several firms for remittances and they are behaving similarly but using another method of remittance in the months that we do not observe a remittance in our data.

However, another possibility is that when salary or remittance is not observed in a month for an individual, this reflects the fact that the individual was not paid or did not remit. In other words, it may be more accurate to treat some of the missing observations as zero rather than missing. This may be particularly likely to be true for remittances where individuals may not remit every month. Informal conversations with foreign workers in the UAE suggest that they tend to remit once per month after receiving their paychecks, but our observed data suggest that individuals remit less frequently than once every month.

We construct an alternative measure of salary where we replace the measure of salary in months for which an individual is not observed to receive a salary disbursal with zero. This is only done for months in which the individual receives a salary in both the previous calendar month and the consecutive calendar month. Observations are kept as missing if the entire firm does not disburse a salary in that month (as this suggests that they may have chosen to pay salaries out through another method that month). Similarly, we also construct an alternative measure of remittances where we replace the value of remittances in months for which no remittance transactions are observed in the data with zero. This is only done for months between the time in which the first and last remittance transactions are observed in the data. This approximately doubles the total number of matched observations relative to the sample that is matched by positive observations of remittance transactions and salary disbursals.

Column 4 of Table 1 shows the characteristics of the sample with unobserved observations of salary filled in as zero. Many of the characteristics of this sample are similar to the other merged sample in terms of age, gender, firm size, Indian nationality, religion and tenure. The average salary for this sample is 1561 dirham per month and the average amount remitted per month is 1326 dirham. Finally, column 5 shows the summary statistics when we assume that unobserved observations of remittances are zero. In this scenario, migrants remit about $60 \%$ of their income.

\footnotetext{
${ }^{20}$ If they forget to bring their customer registration number, they can still remit but all of the information such as name and address will need to be provided to the agent and typed into the system by the agent and they pay lower fees when using their customer registration number.
} 


\section{Relationship between Income and Remittances}

\subsection{Baseline Estimates}

We begin by examining whether remittances vary with fluctuations in earnings. More specifically, we estimate the relationship between the logarithm of individuals' earnings and the logarithm of the amount that they sent in remittances. The relationship presented here is not necessarily the causal impact of fluctuations in earnings on remittance patterns. For example, individuals may choose to exert more effort, work more hours and receive higher earnings in months where they want to remit more to their families. ${ }^{21}$ The results in this section provide the statistical relationship between earnings and remittances whereas the subsequent analyses provide better identified estimates of the causal relationship between earnings and remittances.

The results are presented in Table 2. All the regressions include individual fixed effects, and year fixed effects. The standard errors are clustered at the individual level. ${ }^{22}$ For each estimate, we present a parsimonious specification as well as one that allows the effects of individual characteristics (age, Indian nationality, male and an indicator for high education) to vary by year. Panel A includes only those person-month observations where there is both a remittance transaction and a salary disbursal. Panel B assumes that the migrant did not earn anything in months without a salary disbursal. Panel $\mathrm{C}$ shows the results with the sample where the migrant does not remit anything in months where no remittance is observed in our data.

Column 1 of Table 2 (Panel A) presents the fixed effects estimates of the relationship between salary and remittances in the sample in months where either remittances or salary are not observed are dropped. The results indicate that higher salaries of $10 \%$ correspond with $3.3 \%$ more remittances. All of the estimates in the table are significant at the $1 \%$ level. There are almost no differences in the estimates with and without time-varying effects of worker characteristics. Thus, in the results in the remainder of the paper, we focus on the parsimonious specification with individual fixed effects.

Despite the fact that workers are on fixed contracts, there is substantial variation in their earnings month-to-month that reflects variation in the hours that they have worked. The average absolute value of the change in earnings from the previous month for the same individual is $20 \%$. If we assume that the variation in a worker's earnings is driven primarily by circumstances that are outside of the control

\footnotetext{
${ }^{21}$ This may be a reasonable assumption. Our conversations with managers and workers suggest that month-to-month variation in earnings is driven by variation in hours worked and that the firm managers have much more power over determining who gets additional hours than the workers do.

${ }^{22}$ Appendix Table A.1 includes lags and leads in earnings. The estimated coefficient on the contemporaneous month of earnings remains the same in magnitude and significance as without the leads and lags. The coefficients on the leads and lags are relatively small.
} 
of the individual worker, then the fixed effects estimate of the relationship between log earnings and log remittances provides the income elasticity of demand for remittances.

Panel B displays the fixed effects estimates that correspond with the sample in which the months where salary disbursal is not observed are treated as months in which earnings equal zero. ${ }^{23}$ The coefficients drop substantially. Within-person changes in earnings of $10 \%$ map into $0.5 \%$ higher remittances. However, the results still suggest that fluctuations in earnings month-to-month correspond positively to changes in the remittance behavior of migrant workers.

Panel $\mathrm{C}$ shows the estimates in which unobserved remittance are treated as if there were no remittances. Here the coefficient estimates increase substantially and suggest an earnings-remittance elasticity that is close to one; each additional percent change in earnings maps into the same percent change in remittances. While the results indicate the magnitude of the relationship between remittances and earnings depends on the assumptions made about the months in which transactions are not observed, the sign of the relationship remains the same and significant at the $1 \%$ level.

The results suggest that month-to-month fluctuations in earnings correspond with fairly large changes on the amounts that migrant workers remit each period. These results are consistent with a number of models of remittances. We present a new estimate of the income elasticity of remittances based on high frequency, administrative data. These estimates may be of interest to policy-makers who are interested in leveraging remittances as a mechanism of improving the well-being of households in developing countries. It provides an estimate of how remittances would respond to policies in more developed countries that affect the earnings of migrants.

One limitation of our data is that we need to make some assumptions regarding the implications of months in which we do not observe earnings or remittance transactions. It is reassuring that the positive relationship between month-to-month variation in earnings and remittances persists across several assumptions about months in which payroll disbursal and remittance transactions are not observed. The remaining analyses in the paper use the sample limited to observations where both earnings and remittances are observed.

\section{Seasonalities}

This section explores whether some of the fluctuations in migrants' earnings can be explained by seasonal variation in labor demand and whether remittances move with these seasonal, anticipated

\footnotetext{
${ }^{23}$ In the regressions in Panels B and C, the explanatory variable is the logarithm of earnings plus one. The results are almost identical if we use the inverse hyperbolic sine.
} 
fluctuations in earnings. While the vast majority of workers in the UAE are on multi-year contracts, seasonal variation in demand can affect monthly earnings through the amount of hours worked.

Figure 1 shows the coefficients corresponding to each month in a regression with individual and year fixed effects where the omitted category is January. ${ }^{24}$ The dotted lines give the $95 \%$ confidence interval. The corresponding regression output is shown in Appendix Table A.2, where the odd columns display the full sample and the even columns display the observations where the individual has earnings observations for all 12 calendar months. While there is unlikely to be seasonal selection given that most workers are on multi-year contracts, we look at the sample with all 12 months to address the possibility of seasonal selection. These estimates demonstrate that there is substantial variation over months in both earnings and remittances. Earnings dip in September and October; in those months, earnings are about $4 \%$ lower than in January. There are smaller dips in earnings of around $1.5 \%$ in February and June. Earnings peak in December when they are almost $2 \%$ higher than in January.

Panel B of Figure 1 displays the monthly coefficients for remittances. While there is substantial month-to-month variation in remittances, the seasonal pattern does mimic the pattern in earnings. Remittances decline fairly steadily from May to September. Similar to earnings, remittances are lowest in September.

\subsection{Ramadan}

The most stark seasonal pattern in earnings occurs in September and October, and remittances are also at their lowest point in September. The most likely explanation for this result is the Muslim holiday of Ramadan. One implication of Ramadan for worker productivity is that adult Muslims are required to fast from dawn to sunset for 30 days. ${ }^{25}$ As stipulated in the Federal Law Number 8 of 1980, the standard work day must be reduced by 2 hours during Ramadan in the UAE. Relatedly, many retail businesses reduce the hours that they are open. Thus, the productivity of non-fasting workers is likely to decline during Ramadan as well.

While the timing of Ramadan varies year-to-year following the Islamic calendar, it includes at least part of the month of August in all four years for which we have data. Given that payment occurs on a monthly level and reflects the actual hours worked, payment received in September corresponds with workers' hours in August. Thus, our specification examines the impact of Ramadan on earnings

\footnotetext{
${ }^{24}$ Appendix Figure A.2 shows the average of the logarithms of earnings and remittances by month. Unlike the regression coefficients, these estimates do not remove individual and year fixed effects. The general patterns with the large troughs in autumn are similar to those shown in Figure 1.

${ }^{25}$ For example, Schofield (2014) demonstrates that fasting during Ramadan decreases the productivity of rickshaw workers in India.
} 
and remittances in the subsequent month. Ramadan spills over into September in 2009 and 2010 and into July for 2012.

We focus on the impact of the timing of Ramadan on earnings and remittances. The measure for Ramadan is lag of the number of days of Ramadan in the month (divided by 10). ${ }^{26}$ The results are presented in Table 3. The odd columns include the full sample while the even columns are limited to the sample of individuals for whom we have an earnings observation for each of the 12 months. Panel A shows that 10 days of Ramadan is associated with $1.2 \%$ lower earnings in that month relative to months without Ramadan. Restricting the sample to individuals for which we have data covering the twelve months does not have much effect on the estimates. Interestingly, the magnitude of the impact of Ramadan on remittances is about twice as large. All of the estimates are significant at the $1 \%$ level.

Panel B makes use of the fact that religion is available in MOL database. We look at the interaction of the months covered by Ramadan and an indicator for whether the worker is Muslim. While aggregate productivity falls during Ramadan, we expect the productivity of Muslims to fall even more due to fasting. Thus, the interaction provides an additional test of whether the drop in earnings that we see in this time period is in fact driven by Ramadan. Ten days of Ramadan reduces the earnings of non-Muslim workers by about $0.6 \%$. The impact of Ramadan is much larger among Muslims, who experience an additional 1.8\% drop in earnings on top of that during the holiday compared to their non-Muslim counterparts. Non-Muslims reduce the amount of their remittances by around $2 \%$ during Ramadan. Muslims further reduce the amount that they remit by an additional $1.4 \%$ and this is significant at the $5 \%$ level. Workers can anticipate the earnings reductions associated with Ramadan, but they still reduce their remittances.

Part of the difference in the effects on remittances between Muslims and non-Muslims may stem from differences in consumption demand either by families at home or by the workers in the UAE rather than declines in the migrants' income during Ramadan. To examine this concern, we also look at heterogeneity in the effects of Ramadan by the share of migrants who are Muslim in each migrant's country of origin. ${ }^{27}$ Families in countries without a substantial Muslim population and who are not Muslim themselves are unlikely to experience changes in consumption demands around the time of Ramadan. In contrast, consumption demands may change for Muslim families observing Ramadan or for non-Muslim families who are in countries with a sizable Muslim population. ${ }^{28}$ Among a sample

\footnotetext{
${ }^{26}$ Appendix Table A.4 presents results where Ramadan is an indicator variable that equals 1 if the lag of Ramadan overlaps with at least part of the month.

${ }^{27}$ In the top three countries of origin, more than $70 \%$ of Pakistani and Bangladeshi migrant workers in the UAE are Muslim whereas about $15 \%$ of Indians are Muslim. There are also several countries with substantial number of migrants in the UAE where almost none of the migrants are Muslim, such as Thailand.

${ }^{28}$ For example, many non-Christians in the United States celebrate Christmas and buy presents for friends and family.
} 
of non-Muslim workers in the UAE, we run the following regression for individual $i$ in month $t$ from origin country $j$ :

$$
y_{i j t}=\alpha_{0}+\alpha_{1} R_{i t}+\alpha_{2} R_{i t} \times \text { MuslimShrOrigin }{ }_{j}+\delta_{i}+\delta_{t}+\epsilon_{i j t}
$$

where $R_{i t}$ is an indicator for whether the month included Ramadan at all and MuslimShrOrigin is the total share of migrants in the UAE from the migrant's origin country who are Muslim. ${ }^{29}$ The coefficient on $\alpha_{1}$ gives the impact of Ramadan when none of the migrants from a country are Muslim. Adding $\alpha_{1}$ and $\alpha_{2}$ gives the total impact of Ramadan for workers from countries where all the migrants in the UAE are Muslim.

The results are presented in Table 4. If remittance patterns are driven by consumption demands by workers' families around Ramadan rather than by the declines in migrants' earnings, then we would not expect to see a fall in the remittances of non-Muslim workers from countries without a substantial Muslim population. However, the results do not support this alternative hypothesis. Remittances fall significantly (and follow the impact of Ramadan on earnings) for both Muslim and non-Muslim workers from countries with no Muslim migrants in the UAE.

Another possibility is that remittances and earnings fall because Muslims are more likely to return home to visit for this holiday. Given that the regressions drop observations of months in which either remittances or earnings are not observed in the data, this can only be consistent with the results if they are only paid for part of the month because many workers are returning home for part of the month, and they remit a smaller amount because they are carrying cash home with them. To test for the possibility that travel by migrants during Ramadan is driving the patterns observed, Appendix Figure A.3 presents the kernel density of the logarithm of earnings in the months of Ramadan as compared with other months. The results demonstrate that the distribution of earnings shifts slightly to the left during the Ramadan. If the drop in earnings and remittances were explained by a sizable fraction of workers leaving the UAE for parts of the month that correspond to Ramadan, we would expect the distribution of earnings during Ramadan to be bimodal with a cluster of workers earning a small fraction of their usual salary rather than a shift in the whole distribution.

Given that information about income drops associated with Ramadan is easy to verify by families at home, this type of income fluctuation is considered public. Thus, the fall in remittances associated with Ramadan is consistent with the model of private information. Ramadan is also perfectly

\footnotetext{
${ }^{29}$ We switch to an indicator for months of Ramadan because it is difficult to interpret the interaction between two continuous variables. Appendix Table A.4 shows the parsimonious effects of the Ramadan indicator.
} 
anticipated. Under the traditional version of the permanent income hypothesis, the fact that remittances move with Ramadan rejects the idea that migrants smooth remittances over anticipated income fluctuations.

\section{Weather Shocks}

There is a large literature that uses rainfall shocks as exogenous shocks to income to test for consumption smoothing (Paxson 1992, Wolpin 1982). In addition to looking at rainfall, we consider heat shocks in this context. We use daily temperature data from the World Meteorological Organization for five cities in the UAE: Abu Dhabi, Dubai, Fujairah, Ras Al-Khaimah and Sharjah. Thus, variation in weather is across both time and geographic space. We aggregate the daily information to the monthly level to merge into the monthly level earnings disbursal information. We calculate an average maximum temperature that averages all of the maximum daily temperatures in that city and month. We also calculate an average precipitation per month in each city by averaging across days in the month.

In Figure 2, the dots and the squares display the average maximum temperature in Fahrenheit and the average precipitation in inches across the months and cities in the data, respectively. The bands around the dots and squares provide information on the variation across cities in temperature and rainfall in each month. The upper band indicates the maximum value for a single city in that month and the lower band indicates the minimum value for a single city. Temperatures in the UAE are quite high in the summer with daily maximum temperatures exceeding 100 degrees Fahrenheit from May to September. The bands show that there is considerable variation across cities over the sample period. Rainfall is generally fairly low in the UAE with winter being wetter and March being the month with the greatest rainfall in the sample period. There is even more variation in rainfall across cities than there is in temperature. While the figure provides a sense of seasonal variation in weather outcomes, the shocks are the deviations of the weather outcome in that city and month.

We consider whether worker productivity, and their corresponding earnings, declines when the weather conditions are extremely hot or when it rains. These weather shocks are likely to affect the productivity of workers who are working outside. Many migrant workers are employed in the construction sector where productivity has been found to be negatively affected by rain and heat (Assaf and Al-Hejji 2006).

To estimate the impact of weather shocks on the outcomes of migrant workers, we include city by month fixed effects. The weather measure represents the deviation of a city's weather realization in that month from the average weather realization experienced in that city in that month. Thus, we 
remove the impact of seasonalities and focus on weather shocks that deviate from standard seasonal patterns in rainfall and temperature.

The results are presented in Table 5. The independent variable is the shock in average precipitation in Panel A and the shock in average maximum temperature in Panel B. The odd columns present the results for the full sample of workers and the even columns present the results with the interaction of the weather shock with an indicator for whether the worker is in an outdoor occupation. Appendix Table A.3 shows the results where the independent variables are measured in the shocks to the days of rainfall and the days where the maximum temperature fell into various ranges. The results are similar with measuring weather shocks in days per month rather than average units (of heat or rainfall) per month.

The estimates in Panel A indicate that rainfall shocks correspond with a reduction in earnings. A standard deviation increase in precipitation corresponds with a $1 \%$ fall in earnings and a slightly smaller response for remittances. As shown in the odd columns of Panel B, increases in the shocks to maximum temperature also reduce earnings and remittances. A standard deviation increase in the maximum temperature corresponds with a $4 \%$ decline in earnings and a $12 \%$ drop in remittances.

One important concern with the latter outcome is that variation in weather may affect consumption demands within the UAE directly rather than working solely through the channel of weather. For example, in very hot temperatures, workers may prefer to pay more to eat at air-conditioned restaurants rather than at cheaper restaurants. The next set of results help us examine whether the impact of weather shocks on remittances is primarily driven by how the weather shocks affect earnings in that month. We examine heterogeneity in the impact by whether the individual is working outside in the even columns. The negative effect of rainfall shocks on earnings is significantly larger for outdoor work as compared with indoor work. The interaction is negative but not significant at the standard levels for remittances. While higher temperatures lead to significantly lower earnings and remittances for workers in indoor positions, the negative effect is significantly larger for those working outdoors. Overall, these results support the idea that the mechanism of the weather shocks is that it reduces the amount of time that workers can be productive outside.

The results suggest that remittances fall in response to these types of unanticipated, transitory income shocks. Negative weather shocks are easy for families at home to verify and are considered public. Thus, the results are consistent with the model of asymmetric information where households at home are willing to receive lower remittances in months with extreme heat and rain. Whether the income fluctuation is unanticipated as with the weather shocks or anticipated as with the seasonalities does not affect the relationship between migrants' earnings and remittances. 


\section{Labor Mobility Reform}

We exploit a labor reform that was announced in December 2010 and implemented in January 2011 to examine the impact of a positive, unanticipated, permanent income shock on remittance behavior. Prior to the reform, workers needed written permission, called a no objection certificate (NOC), from their existing employer to change firms at the end of their multi-year work contracts. Without written permission from their employers to change firms, workers could not directly change firms and either had to sign a new multi-year contract with their existing firms or leave the UAE for at least six months. The reform removed the NOC requirement at the end of the contract but made no changes to the terms and requirements during a contract. Thus, the reform gave workers more bargaining power with their employers by reducing the monopsony power of their existing employers. Naidu, Nyarko and Wang (2014) demonstrate that this reform has a very robust, positive effect on the earnings of existing workers.

We begin by replicating the baseline analysis of the impact of the reform on workers' earnings within our sample of individuals for whom we also observe remittance transactions. ${ }^{30}$ Focusing on 7 periods of data around a contract expiration for each worker, we look at outcomes before and after the reform as well as before and after the worker's contract expires. Because the reform only applies to workers after their contracts expire and after the implementation of the reform, we can identify the causal impact of the reform with this difference-in-difference approach. More specifically, we estimate the following:

$$
y_{i t}=\beta_{0}+\beta_{1} \text { Post } 2011 \times \text { PostContractExpire } e_{i t}+\beta_{2} \text { Post } 2011 \times \text { ContractExpire }_{i t}+\delta_{i}+\delta_{t}+\epsilon_{i t}
$$

where Post2011 is an indicator for the calendar periods after the implementation of the reform in January 2011, PostContractExpire it $_{\text {is }}$ an indicator for the three periods after an individual's contract expires and ContractExpire ${ }_{i t}$ is an indicator for the period that a contract expires. The regressions also include year-month fixed effects and individual fixed effects. The estimates of $\beta_{1}$ and $\beta_{2}$ provide information on whether the effects of contract expiration (estimated in a 7 month window around the expiration) after the reform are different from the effects before the reform.

The results are presented in Table 6 . The first column shows that the reform led to an increase in earnings of about $3.5 \%$ in the month of the contract expiration and $4 \%$ in the three months after

\footnotetext{
${ }^{30}$ See Naidu, Nyarko and Wang (2014) for additional details on the reform, the estimation strategy and the robustness checks.
} 
the worker's contract expired. ${ }^{31}$ We see that remittances also increase as a result of the reform. They increase by about $12 \%$ in the three months after the worker's contract expires, and by $6.5 \%$ in the month of the worker's contract expiration. While the estimates for remittances are larger in magnitude than for earnings, they are not significantly different from the earnings effects.

Unlike weather shocks and seasonalities which are transitory, the labor reform led to a permanent increase in income. The results suggest that remittances move with this type of income change, indicating that whether an increase in earnings is transitory or permanent does not affect the relationship between earnings and remittances. This income shock is likely to be public as this reform increases the average earnings of all migrant workers following their contract expiration. This is consistent with the model of asymmetric information where remittances are payments associated with migrants' observable income.

\section{Time in the UAE}

\subsection{Empirical Strategy}

So far, the income fluctuations that we have examined have been shocks that are likely to be publicly known and relatively easy for families at home to verify. We now examine how migrants' earnings change with their time in the UAE. The approach taken is similar to estimations of the rates of economic assimilation of immigrants in the literature. We estimate the following equation for individual $i$ in year-month $t$ :

$$
y_{i t}=\beta_{0}+\beta_{1} \text { TimeinU } A E_{i t}+\delta_{i}+\delta_{T}+\epsilon_{i t}
$$

where the dependent variable is either the logarithm of earnings or remittance of person $i$ in month $t$. The variable, TimeinU AE, is the number of months (divided by 10) that individual $i$ has been in the $\mathrm{UAE}$ at period $t$. We are interested in the coefficient, $\beta_{1}$, which provides the impact of an additional 10 months of time in the country. The regressions also include individual fixed effects as well as year fixed effects and month fixed effects. Equation 3 assumes that the relationships between time in the UAE and earnings and between time in the UAE and remittances are log linear. We examine the validity of this assumption in two ways. First, we change the functional forms to include a quadratic function of time in the country. Second, to allow for full flexibility in the relationships, we estimate

\footnotetext{
${ }^{31}$ The magnitude of the effect is slightly different from those reported in Naidu, Nyarko and Wang (2014) because we restrict the sample to those for whom we also have remittance transaction information, but the direction of the effect is the same.
} 
them with an indicator variable for each month that a worker has been in the UAE.

A common concern with this type of estimation is that the returns to assimilation in the host country are driven by selection into who stays (Borjas 1999). We do several things to address this concern. First, in addition to running equation 3 on the full sample of migrants, we also estimate it with a sample of migrants who are in their first multi-year contract. Given that migrants who leave without completing a contract must pay for their airfare home while those costs are borne by the firm for migrants who complete the full contract, the vast majority of migrants leave after a contract expires rather than mid-contract. Thus, this sample restriction should minimize the effects of selection. Second, we implement a bounding exercise to estimate the maximum effect that selection can have on the estimates in Section 11.

One advantage of our data is that the information about time in the UAE within the firm is based on administrative records from the MOL on workers' first employment visas in the UAE. Unlike analyses that utilize survey data, the issue of measurement error is unlikely to be a large concern. While time in the host country is likely to be highly correlated with employer tenure, we separate the effects of firm tenure and time in the UAE in Appendix Table A.5. ${ }^{32}$ For the purposes of our analysis, however, it is not important if the returns that we capture are specifically the returns to experience in the country rather than within the firm.

\subsection{Estimates of Time in the UAE on Income and Remittances}

Figure 3 presents the fully flexible coefficient estimates of each separate month of time in the UAE. The omitted category is the first month that the worker enters the UAE. In Panel A, the dependent variable is the logarithm of monthly earnings. The figure shows a strong positive within-individual relationship between time in the UAE and earnings. For most workers in the sample, the typical contract is for 36 months. Thus, it is interesting that the increase in earnings happens fairly linearly throughout that period; this suggests that growth in individuals' earnings occurs within the life of a labor contract. These estimates suggest that workers with more experience in the UAE either get higher wages or more hours within a labor contract. In contrast, Panel B indicates a strong negative within-individual relationship between experience in the UAE and remittances. Both panels provide visual support for the assumption of a linear relationship.

The results corresponding to equation 3 and to the quadratic specification are presented in Panel

\footnotetext{
${ }^{32}$ Tenure is defined as the number of months (divided by 10) that individuals have spent at their current firm. The ability to identify both time in the UAE and firm tenure is driven by workers who change employers and for whom both of their employers are in the payroll processing data. Controlling for tenure does not have much effect on the relationship between experience in the UAE and earnings or remittances.
} 
A of Table 7. Panel B displays the same estimates for the sub-sample of migrants in their first labor contract in the UAE. According to the linear specification, controlling for time-invariant characteristics of individuals, a 10-month increase in time in the UAE corresponds with approximately $1.7 \%$ higher earnings. The estimates are significant at the $1 \%$ level and the magnitudes are economically large. The estimates of the quadratic relationship and in the first contract-only sample are almost identical.

The next two columns of Table 7 display the corresponding results where the dependent variable is the logarithm of remittances. The relationship between time in the UAE on remittances is negative. The linear specification suggests that each additional 10 months of tenure leads to a 9.6 percentage point decline in the amount remitted. The quadratic specification suggests a slightly smaller impact of an additional 10 months of time in the UAE (8.3\%) compared to the linear specification. The impact of time in the UAE on remittances is slightly smaller when we limit the sample to those in their first contract.

The previous results have shown that remittances move in the same direction as income changes associated with seasonalities, weather shocks and the labor reform. However, the results here are quite different. While earnings increase over time in the UAE, average remittances decline over time. This result is consistent only with a model where remittance payments are part of income-sharing contracts affected by asymmetric information.

\subsection{Asymmetric Behavior Based on the Earnings-Tenure Profile}

We examine an additional prediction of the framework in which migrants exploit private information about the evolution of their earnings. While on average migrants' earnings increase over time, there is heterogeneity in this across individuals. Migrants who experience a negative earnings-tenure profile have less incentive to hide this information than migrants who experience a positive earnings-tenure profile. Given the literature that documents that wages are sticky downwards, it may be surprising that earnings fall for a substantial number of migrant workers in the UAE. First, in informal conversations with migrant workers in labor camps, some did mention that their earnings had fallen over time. We think this is driven by a shift in hours or wages where good workers are given more overtime or higher wages. ${ }^{33}$ Second, this correlation is between real earnings and time and workers' earnings which may be partially eroded by the lack of raises to adjust for inflation. Finally, this labor market is quite unique, so it is possible that the features of labor markets that drive nominal wage rigidity, such as efficiency wage stories, are not relevant here.

We examine asymmetries in the impact of changes in time in the UAE on remittances by whether

\footnotetext{
${ }^{33}$ We do not observe hours worked and cannot test this idea directly.
} 
the individual experienced a positive or negative earnings-time profile. In other words, we estimate:

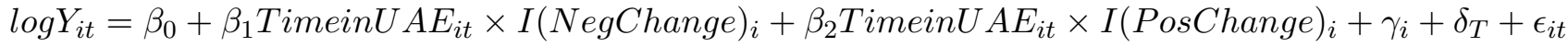

where we include the interaction between time in the UAE, denoted by TimeinUAE, and a timeinvariant indicator for whether the person experienced a positive or negative correlation between time in the UAE and earnings, denoted by $I$ (PosChange) and $I$ (NegChange), respectively. ${ }^{34}$ More specifically, the correlation is calculated with the full earnings sample as the within-person correlation coefficient between all of the observations of time and earnings for individuals who had three or more months of earnings data. We also include individual fixed effects and indicators for month and for year. The coefficient, $\beta_{1}$, provides the impact of each additional 10 months of time in the UAE for individuals for whom the correlation between time and earnings is not positive. The coefficient, $\beta_{2}$, provides the impact of each additional 10 months for individuals for whom the correlation is positive.

The main concern with interpreting the results of this equation is that there are time-varying unobservable differences between the two types of individuals that affect their remittance behavior directly. For example, if individuals with a positive time-earnings profile are in white collar jobs that allow them to bring their families to the UAE and they do so after several periods to allow themselves to settle into their jobs, then an observed drop in remittances over time simply reflects the fact that they remit less when their nuclear family moves to the UAE.

We consider this by comparing individual characteristics and the initial economic behavior of the two groups of workers in Table 8. Column 1 refers to individuals whose earnings decrease over time and column 2 to individuals whose earnings increase over time. The first three rows refer to the initial contract terms. While the differences in the initial terms of the contract are significant at the $5 \%$ level, the differences are economically small. For example, the difference in contract hours is 0.01 hours per day. Those whose earnings rise over time start with a contract salary that is about $4 \%$ higher than those whose earnings fall over time. The difference in average contract length is less than one month. The differences between the two groups in their demographic characteristics are economically small and the difference in their initial remittance is not significant. The ex-ante similarities along observable characteristics between the two types of workers may not be that surprising given that for most workers in the UAE, firms (or the recruiting firms that they hire) screen workers before they are given visas to enter the country. Thus, selection into the UAE is determined by the screening

\footnotetext{
${ }^{34}$ These variables are defined by whether the raw correlation between all observations of earnings and time in the UAE within the individual is positive or negative. The individual must have at least three observations of salary for this correlation to be calculated.
} 
process of firms in addition to the pool of applicants who apply to work in the UAE. In addition, the rates of selection out of the UAE appear very similar for the two groups (Panel B). The probability that a worker leaves the UAE in any given month is about $2 \%$ regardless of whether their earnings are evolving up or down over time. Overall, the similarities between the two groups provide some assurance for the idea that these workers are quite similar at the time that they start working in the UAE, and that it may be unknown to the families at home whether the worker's earnings will evolve positively or negatively over time.

Appendix Figure A.4 presents a histogram of the share of employees in firms with more than 10 workers with positive growth in earnings over time. The mass of the distribution is $50 \%$. This suggests that the positive or negative trends over time in earnings usually occur within a firm. In other words, it is not the case that there are two types of firms, one that pays workers more over time and one that pays them less. This provides additional support for the idea that whether a person earns more over time or not is private information and not based on an observable characteristics like the firm at which he is employed.

When the dependent variable is the logarithm of earnings, by construction $\beta_{1}$ must be negative and $\beta_{2}$ must be positive. This estimation provides magnitudes of the relationship between earnings and time that are useful for evaluating the effects on remittances. The results are presented in the first two columns of Table 9. For individuals for whom the correlation between their time in the UAE and earnings is negative, each additional 10 months of tenure corresponds with a $10 \%$ decline in their wages. For individuals for whom the correlation is positive, an increase in time in the UAE of 10 months maps into an average $11 \%$ increase in their wages.

The next two columns of Table 9 provide the estimates of equation 4 with the logarithm of remittances as the dependent variable. For individuals with a negative correlation between time and earnings, remittances fall the longer the migrant stays in the UAE. Each additional 10 months in the country corresponds with a decline in remittances of around $11 \%$. This estimate is roughly similar to the impact on earnings over time for this group. However, the relationship between remittances and time looks quite different for individuals with a positive time-earnings profile. While time in the UAE increases the total earnings of this group, more time spent in the UAE leads to very little change in their remittances. An additional 10 months corresponds with $1.5 \%$ less remittances for individuals whose earnings grow over time but this estimate is not significantly different from zero with the inclusion of time-varying worker controls. In other words, while they earn more over time, they remit about the same amount (or less) as the time that they spend in the UAE increases. This implies that the share of income that is remitted declines over time. 
The results are consistent with the idea that migrant workers have private information about the evolution of their earnings in the UAE, and that they share the burden with their families at home when their long-run earnings decline. However, if their earnings evolve positively over time, they continue to remit the same amount or less on average and do not pass along the extra earnings over time abroad. This result is not consistent with the models of remittances as altruism or exchange.

\subsection{Asymmetric Behavior Based on Home Connections}

We consider the idea that individuals who have more connections to communities at home are less able to hide growth in their earnings over time. Co-workers from the same community may have information about how a person's earnings evolve over time within the company and be able to report this information to family members in the home country.

The data include some information on the receiving location of the remittance. There is substantial variation in the type of information on the receiving location of the remittance over time, country and over types of transactions. For many transactions, there is only country-level information available. For migrants from India, we cleaned and coded a string variable that contained the state that the remittance was sent. ${ }^{35}$ We then create a variable for home connections that is based on the share of workers in the firm that are from the same state in India. To examine heterogeneity by these home connections, we construct an indicator variable for whether a person's connections are above or below the median share of connections of $17 \%$. For a different (and smaller) subset of remittance transactions, we have a code identifying the district in which the transfer was received. Thus, we are also able to examine whether the person's share of co-workers from the same district is above or below the median for this measure, $7 \%$.

One concern is that individuals who have more co-workers from the same home state or district are different than individuals with few co-workers who are from the same home community. We examine baseline characteristics of individuals who have more or fewer connections within their firm to their home state and to their home district in columns 4 through 9 of Table 8. For most characteristics, there is either very little statistical or economic difference between individuals with more connections to their home state as compared with those with fewer connections. For example, while the difference in the initial contract hours is statistically different between the two home state groups, a difference of 0.01 hours (or less than one minute) per day is economically not important. The one exception with the home state groups is that the difference in initial remittance between the two groups is statistically significant and not that small in magnitude at about $6 \%$. However, it is reassuring that this difference

\footnotetext{
${ }^{35}$ Migrants in the UAE are from 36 states and territories in India.
} 
is not significant in the home district groups. For the home district groups, there is a sizable and significant difference in initial contract salary. However, for both of these characteristics, the bias may work in the opposite direction as those with fewer connections remit more in their initial remittance. Finally, as shown in Panel B, the rates at which workers exit the UAE is similar regardless of whether they had more or fewer connections to their home state within their firm.

In Panel A of Table 10, we present the impact of time in the UAE on the outcomes by both home connections and whether the individual's earnings increase or decrease over time. Panel B shows the same results where home connections are defined at the district level rather than at the state level. In columns 1 and 2, the relationships between time in the UAE and earnings for positive and negative changers are not significantly different for those with more or fewer home connections. This is reassuring as it suggests that differences across these two groups, those with more or fewer home connections, do not have different gradients in earnings over time.

The results in columns 3 and 4 are particularly interesting. They show that remittances decline significantly over time regardless of the degree of home connections for workers whose salaries decline over time. However, as shown in column 4 of Panel A, for workers whose salaries increase over time, remittances increase for those who have more state connections. For individuals with fewer state connections, the magnitude of the effect is much smaller and not significantly different from zero (Panel A colum 3). The asymmetry in behavior by connections is also present when we measure connections at the district level in Panel B. Those who earn more over time remit significantly less when they have fewer connections to their home within the firm (column 3) and remit an amount that is not significantly different from zero if they have more connections. While the gap in behavior by above or below median connections for those with a positive earnings-time gradient exists for both measures of connections, the effect of more than median connections is positive (and significant) with the home state measure but it is not positive and significant with the home district measure. This is most likely explained by the fact that the thresholds for above or below median are different depending on the measure.

These results suggest that having more co-workers from the same area may reduce the likelihood that migrant workers can fully hide whether they are earning more over time in the UAE. This can occur because co-workers provide monitoring. An alternative interpretation is that having more coworkers from the same place maintains the affinity that migrants have with their families over time. The latter interpretation can still be consistent with the model of asymmetric information where migrants have less incentive to exploit private information about income gains when they feel more affinity to their home communities. These results provide additional support for the theory that the 
best model for the remittance behavior of migrants in the UAE is one where remittances are viewed as an income-sharing payment to families at home. Thus, they are less likely to remit upward changes in income that can be hidden from their families at home, but they are willing to pass along negative long-run changes in income to their families.

\section{Alternative Explanations}

The main alternative explanation is that the observed patterns in remittances are driven by demand shocks experienced by households at home rather than by variation in the earnings of migrants in the UAE. Among the income fluctuations that we consider easy to observe by households at home, this concern is largest for the estimates exploiting seasonalities and Ramadan. As discussed previously, it may be plausible that households at home, especially those who also observe Ramadan or are from Muslim countries, experience a change in their demand for remittances around this holiday. For example, if consumption drops during Ramadan for households in the sending countries, this may explain the drop in remittances. However, the results of Table 4 that look at the remittance behavior of non-Muslim migrants from areas without a large Muslim population do not support this interpretation.

Reassuringly, demand shocks by households at home cannot explain the variation in remittance patterns using weather shocks and the labor reform in the UAE. It is very unlikely that random deviations from standard seasonal patterns in rainfall and heat in a city and month in the UAE are correlated with demand shocks of households at home in different sending countries. Similarly, the identification strategy examining the effects of the labor reform use individual variation in the expiration dates of their contracts, and it seems very unlikely that the contract expiration dates which depend only on the start date of the contracts three years in advance are correlated with contemporaneous demand shocks of households at home.

A second (and related) alternative hypothesis is based on the idea that variation in the earnings of migrants reflects their own choice in how many overtime hours to work or how much effort to exert. In conversations with migrants in the UAE, our field work suggests that low skilled migrants do not have much power in determining the amount of overtime that they work. Unfortunately, we cannot observe hours worked per month or other measures of effort by the workers. This concern is most relevant for the estimates of the returns to time in the UAE for workers whose earnings evolve up and down over time. It is possible that workers with a positive earnings-time gradient are exerting more effort over time while workers with a negative earnings-time gradient are exerting less effort over 
time. The patterns in effort may be driven by different expectations for sharing with their families at home. There may be two groups of individuals - those with sharing rules that involve a proportion of their earnings and those who are expected to remit a fixed amount each month. Similar to predictions of models of sharecropping where sharecroppers have less incentive to exert effort than tenants that pay fixed rent, the former group under income sharing contracts may exert less effort and earn and remit less while the latter group under fixed payment contracts may exert more effort because they can keep all of the earnings from their additional effort. This alternative explanation is consistent with the results of Table 9 but not with those of Table 10. Under the alternative story where the results for earnings and remittances are driven by effort and different types of contracts, co-workers from the same home area do not provide information to families at home; more co-workers from the same home area may instead increase a worker's affinity towards home. In this case, variation in the number of co-workers from the same place should affect both earnings and remittances. However, this is not consistent with Table 10, which demonstrates that having more co-workers from the same place at home does not affect earnings but has asymmetric effects on remittances.

Finally, it is possible that the estimates of the returns to time in the UAE reflect changes in the consumption patterns of migrants. Over time, migrants begin to acclimate to the higher prices for goods and services in the UAE or feel less affinity for family members at home. This mechanism leads them to keep more of their income for their own consumption in the UAE. This is consistent with the results of Table $7 .{ }^{36}$ Under this alternative story, the observability of income does not matter and we should see any positive income fluctuations correspond to lower remittances the longer that a migrant remains in the UAE. Appendix Table A.6 shows that this is not empirically true; the signs on the interactions between time in the UAE (measured in months divided by 10 in column 1 or as an indicator for having been in the UAE more than 21 months in column 2) and log earnings are very small in magnitude and positive rather than negative. In other words, migrants do not remit less of all fluctuations in their income the longer that they stay in the UAE.

\section{Selection out of the Data}

A key potential concern for the estimates presented in the paper is that selection of migrants out of the sample could affect the results. We address this concern by imputing earnings and remittances of individuals who leave the payroll sample using a method proposed by Manski (1990). The key idea

\footnotetext{
${ }^{36}$ For this alternative story to be consistent with Tables 9 and 10, heterogeneity by individual type and home connections reflects very specific, unobserved differences across individuals in their consumption demands in the UAE rather than variation in the incentives and ability to hide income.
} 
is to examine whether the results are robust to fairly extreme assumptions about the individuals who are exiting the sample.

We make the assumption that the earnings of individuals in the periods in which they exit the sample would look like the 90th and the 10th percentile of their log earnings distribution. Similarly, we constructed imputed values for remittances by assuming that if they had remained in the sample, they would have remitted an amount equivalent to the 90th and 10th percentile of the distribution of their log remittances. This strategy maximizes the potential impact of sample selection on the estimates.

The baseline estimates that use the imputed values of remittances and earnings are displayed in Table 11. Column 1 presents the estimates where we assume that individuals who attrite from the data set would have had earnings and remittances in the 90th percentile, and column 4 presents the estimates were the attriters would have had earnings and remittances in the 10th percentile. The estimates are similar to each other and just slightly larger than the baseline fixed effects estimate presented in Table 2. The stronger assumption is that individuals who leave the data would have 10th percentile earnings and 90th percentile remittances, or 90th percentile earnings with 10th percentile remittances. These estimates are displayed in columns 2 and 3, respectively. Under these assumptions, the earnings elasticity of remittances is smaller than when we ignore selection effects. However, the economic magnitude is still substantial; a $10 \%$ increase in earnings corresponds with a 2 to $2.5 \%$ increase in remittances. These estimates are significant at the $1 \%$ level.

The other estimates presented in the paper are robust to addressing selection with this bounding exercise. Addressing selection with this bounding exercise has the largest impact on the estimates of the impact of time in the UAE on remittances. This is not surprising as those who remain in the UAE for longer amounts of time are likely to be different from individuals that choose to exit the country. We display the impact of time in the UAE (filled in to assume that migrant workers stay on an additional period) on the imputed values of remittances and earnings in Panel A of Table 12. The relationship between time in the UAE and earnings remains positive and significant at the $1 \%$ level in the case of the high earnings imputations and at the $10 \%$ level in the case of the low earnings imputations. Similarly, the relationship between time and remittances remains negative and significant at the $1 \%$ level. After adjusting for selection, being in the UAE for an additional 10 months corresponds with $1.6 \%$ to $3.2 \%$ lower monthly remittances.

Panel B of Table 12 presents the impact of selection on the asymmetries in the earningsremittances relationship given by equation $4 .{ }^{37}$ The range of the effects of selection on these estimates

\footnotetext{
${ }^{37}$ We simply forward fill the indicator for whether there is a positive correlation between earnings and time and do not
} 
is fairly tight and the conclusions remain unaltered. Individuals who stay longer in the UAE remit less if their earnings tends to decline; for each additional 10 months in the UAE, they earn 8 to $10 \%$ less and remit 6 to $9 \%$ less. However, for individuals for whom their earnings increases over time, their earnings increase by about $7 \%$ for each additional 10 months that they remain in the UAE but their remittances remain constant over time.

\section{Conclusion}

Using new high frequency data on earnings and remittances, we investigate the impact of fluctuations in earnings of migrant workers on their remittance behavior. Our results show that remittances move with several types of short-run fluctuations in income, including seasonalities, which are expected, and weather shocks, which are unexpected. They also move in the same direction as a long-run shock to income associated with a labor reform that gave workers more bargaining power with their employers. These results are consistent with several models, including remittances as altruism, exchange payments or payments in an income-sharing contract under asymmetric information. The estimates of the impact of the labor reform are not consistent with a model of altruism in which migrants attempt to smooth consumption over time.

While the labor reform was a public shock to the permanent income of migrants, we also examined a change to permanent income that is privately known by the migrant. We identified that on average earnings tend to increase steadily over time and remittances tend to fall steadily over time. This suggests that migrants may treat fluctuations that can be hidden differently from those that are easily observed by families at home. Furthermore, this result is driven by a particular type of asymmetric behavior; those who earn less over time remit less but those who earn more over time remit about the same amount. This result is only consistent with the model of asymmetric information driving remittance payments.

These results have several policy implications. International migration represents an important opportunity for migrants to increase their income, and remittances are a large source of transfers for many households in developing countries. Understanding the motivations for why migrants remit can be important for policies that may affect the remittance behavior of migrants. It can also be important for devising appropriate financial products for migrants. The results may be relevant in thinking about products that give migrants more control over the assets that they remit, such as those studied in Ashraf et al. (2014).

re-calculate this indicator based on the additional imputed month. 
Migrants in the UAE are remitting the majority of their earnings each month. At the same time, their behavior reflects the idea that when given the opportunity, they prefer to keep more of the earnings that are hidden from their families. While we show some suggestive evidence that networks of workers from the same place in the home country may provide monitoring, more research is needed to fully understand the complex interplay between migrants and families at home. While the data used in our analysis only includes information on earnings, remittances and demographics of the migrants in the UAE, the ability to combine data on the migrant's side with high frequency information about the families of the migrants at home would be instrumental in furthering this research agenda. 


\section{References}

[1] Ambler, Catherine. "Don't tell on me: Experimental evidence of asymmetric information in transnational households". Working paper, 2014.

[2] Ashraf, Nava. "Spousal control and intra-household decision making: An experimental study in the philippines". The American Economic Review, pages 1245-1277, 2009.

[3] Ashraf, Nava, Diego Aycinena, A Martínez and Dean Yang. "Remittances and the problem of control: A field experiment among migrants from el salvador". Review of Economics and Statistics (forthcoming), 2014.

[4] Assaf, Sadi A and Sadiq Al-Hejji. "Causes of delay in large construction projects". International journal of project management, 24(4): 349-357, 2006.

[5] Borjas, George J. "The economics of immigration". Journal of economic literature, pages 16671717, 1994.

[6] Borjas, George J. "The economic analysis of immigration". Handbook of labor economics, 3: 1697-1760, 1999.

[7] Carroll, Christopher D. "A theory of the consumption function, with and without liquidity constraints". Journal of Economic Perspectives, pages 23-45, 2001.

[8] Chaudhuri, Shubham and Christina Paxson. "Consumption smoothing and income seasonality in rural india". Working paper, 1993.

[9] Cox, Donald. "Motives for private income transfers". The Journal of Political Economy, pages 508-546, 1987.

[10] De Weerdt, Joachim, Garance Genicot and Alice Mesnard. "Asymmetry of information within family networks". CEPR Discussion Paper No. DP10125, 2014.

[11] Dustmann, Christian and Josep Mestres. "Remittances and temporary migration". Journal of Development Economics, 92(1): 62-70, 2010.

[12] Forstenlechner, Ingo and Emilie Jane Rutledge. "The gcc's "demographic imbalance": Perceptions, realities and policy options". Middle East Policy, 18(4): 25-43, 2011.

[13] Friedman, Milton. Theory of the Consumption Function. Oxford \& IBH Publishing Company, 1957.

[14] Goldberg, Jessica. "The lesser of two evils: The roles of social pressure and impatience in consumption decisions". Working paper, 2010.

[15] Grigorian, David A, Tigran A Melkonyan and J Scott Shonkwiler. "Garbage in, gospel out? controlling for the underreporting of remittances". IMF Working Papers, pages 1-19, 2008.

[16] Human Rights Watch. "Island of happiness: Exploitation of migration workers on saadiyat island, abu dhabi". May 2009.

[17] Jacoby, Hanan G and Emmanuel Skoufias. "Testing theories of consumption behavior using information on aggregate shocks: Income seasonality and rainfall in rural india". American Journal of Agricultural Economics, 80(1): 1-14, 1998. 
[18] Jakiela, Pamela and Owen Whitfield Ozier. "Does africa need a rotten kin theorem? experimental evidence from village economies". Working paper, 2012.

[19] Jappelli, Tullio and Luigi Pistaferri. "The consumption response to income changes". Annu. Rev. Econ., 2(1): 479-506, 2010.

[20] Kapur, Devesh and Randall Akee. "Remittances and rashomon". Center for Global Development Working Paper, (285), 2012.

[21] Kazianga, Harounan and Christopher Udry. "Consumption smoothing? livestock, insurance and drought in rural burkina faso". Journal of Development Economics, 79(2): 413-446, 2006.

[22] Khandker, Shahidur R. "Seasonality of income and poverty in bangladesh". Journal of Development Economics, 97(2): 244-256, 2012.

[23] LaLonde, Robert John and Robert W Topel. Economic impact of international migration and the economic performance of migrants, volume 1B. Elsevier, 1997.

[24] Lucas, Robert EB and Oded Stark. "Motivations to remit: Evidence from botswana". The Journal of Political Economy, pages 901-918, 1985.

[25] Manser, Marilyn and Murray Brown. "Marriage and household decision-making: A bargaining analysis". International economic review, pages 31-44, 1980.

[26] Manski, Charles F. "Nonparametric bounds on treatment effects". The American Economic Review, 80(2): 319-323, 1990.

[27] McElroy, Marjorie B and Mary Jean Horney. "Nash-bargained household decisions: Toward a generalization of the theory of demand". International economic review, pages 333-349, 1981.

[28] Naidu, Suresh, Yaw Nyarko and Shing-Yi Wang. "Worker mobility in a global labor market: Evidence from the united arab emirates". NBER Working Paper 20388, 2014.

[29] Nations, United. "Number of international migrants rises above 232 million", September 2013.

[30] Paxson, Christina H. "Using weather variability to estimate the response of savings to transitory income in thailand". The American Economic Review, pages 15-33, 1992.

[31] Paxson, Christina H. "Consumption and income seasonality in thailand". Journal of political Economy, pages 39-72, 1993.

[32] Rapoport, Hillel and Frédéric Docquier. "The economics of migrants' remittances". Handbook of the economics of giving, altruism and reciprocity, 2: 1135-1198, 2006.

[33] Schofield, Heather. "Economic costs of low caloric intake: Evidence from india". Working Paper, 2014.

[34] Seshan, Ganesh and Robertas Zubrickas. "Asymmetric information about migrant earnings and remittance flows". In "Qatar Foundation Annual Research Conference", 1. 2014.

[35] Wolpin, Kenneth I. "A new test of the permanent income hypothesis: the impact of weather on the income and consumption of farm households in india". International Economic Review, pages $583-594,1982$.

[36] Yang, Dean. "Coping with Disaster: The Impact of Hurricanes on International Financial Flows, 1970-2002". The B.E. Journal of Economic Analysis \& Policy, 8(1): 1-43, June 2008. 
[37] Yang, Dean. "International Migration, Remittances and Household Investment: Evidence from Philippine Migrants' Exchange Rate Shocks". Economic Journal, 118(528): 591-630, April 2008.

[38] Yang, Dean. "Migrant Remittances". Journal of Economic Perspectives, 25(3): 129-52, Summer 2011.

[39] Yang, Dean and HwaJung Choi. "Are remittances insurance? evidence from rainfall shocks in the philippines". The World Bank economic review, 21(2): 219-248, 2007.

[40] Yang, Dean, A Martínez et al. "Remittances and poverty in migrants home areas: Evidence from the philippines". 2005. 
Figure 1: Coefficients from Estimates of Month on Earnings and Remittances

(a) Log Earnings

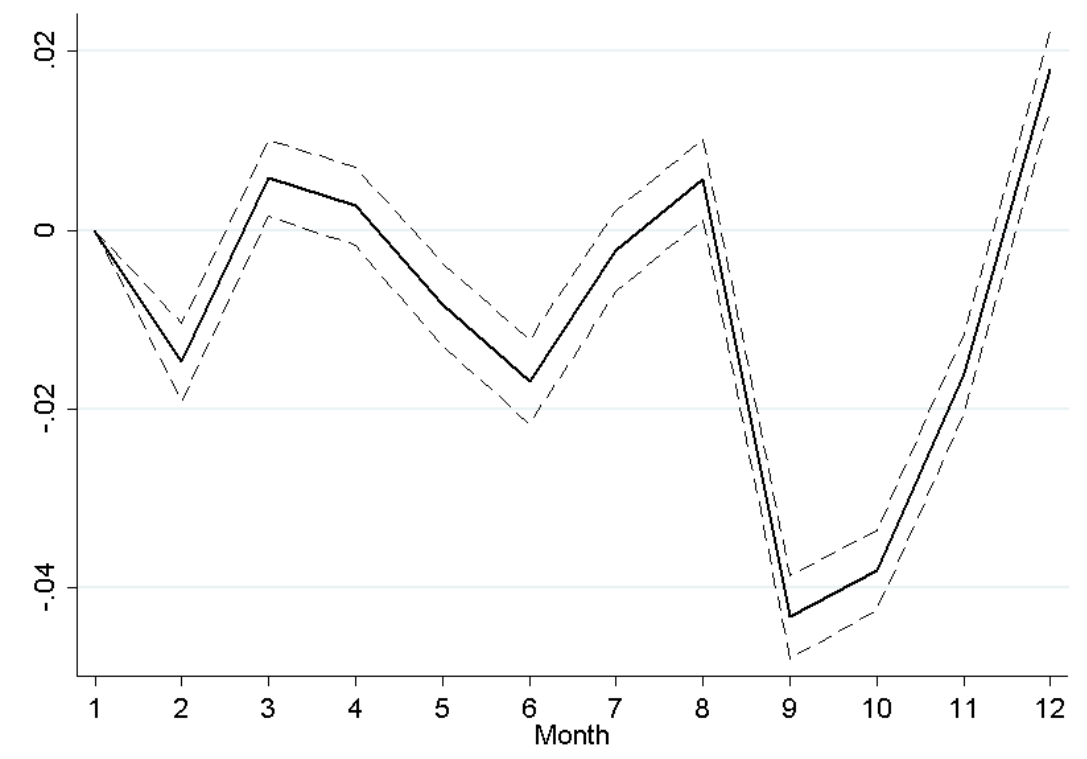

(b) Log Remittances

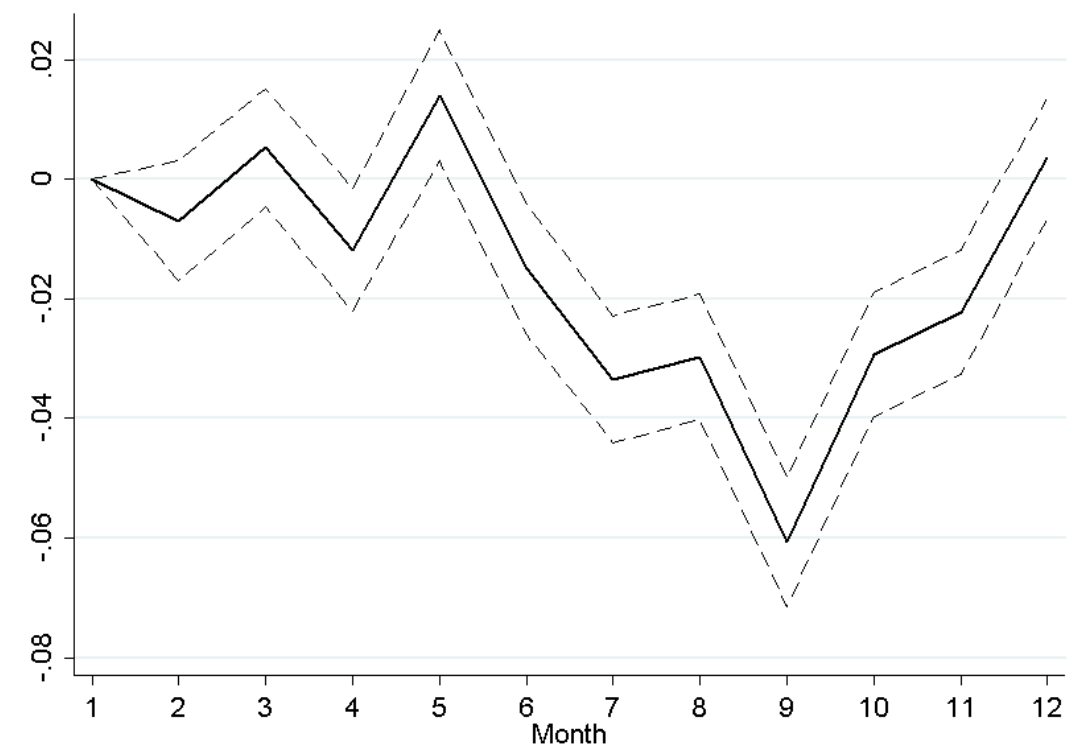

Notes: The estimated coefficients associated with each calendar month is given by the solid line. The regression includes individual fixed effects and year indicators. The omitted category in the regressions is January. The $95 \%$ confidence interval is given by the dashed lines. 
Figure 2: Average Precipitation and Temperature by Month

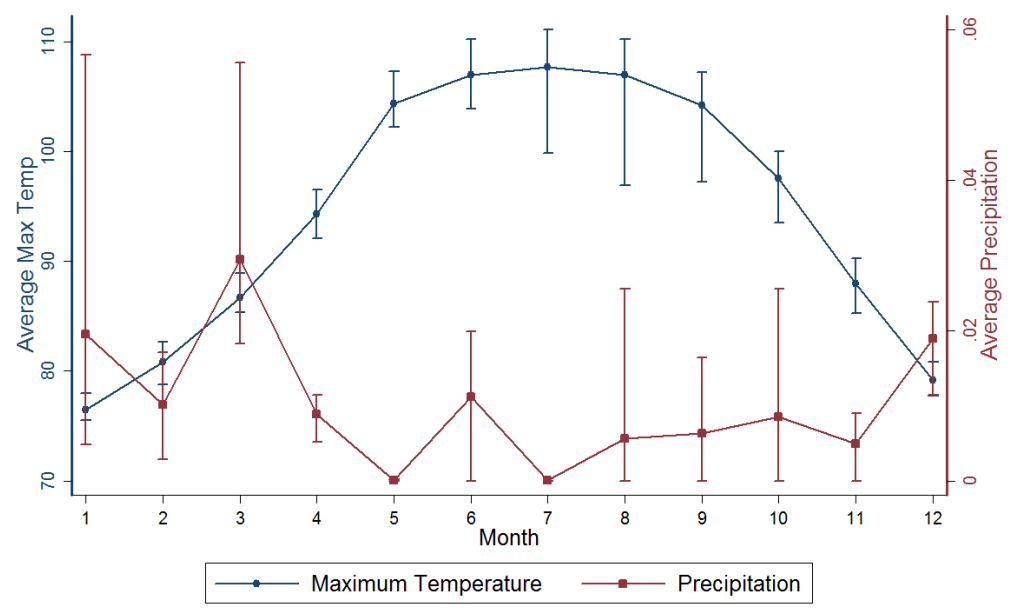

Notes: The dots give the monthly average across all days and cities of the maximum daily temperature. The bands give the value associated with city-level maximum and minimum monthly average. The squares indicate the monthly average precipitation across all days and cities. The corresponding bands provide the city-level maximum and minimum precipitation in that month. 
Figure 3: Coefficients from Estimates of Time in the UAE on Earnings and Remittances

(a) Log Earnings

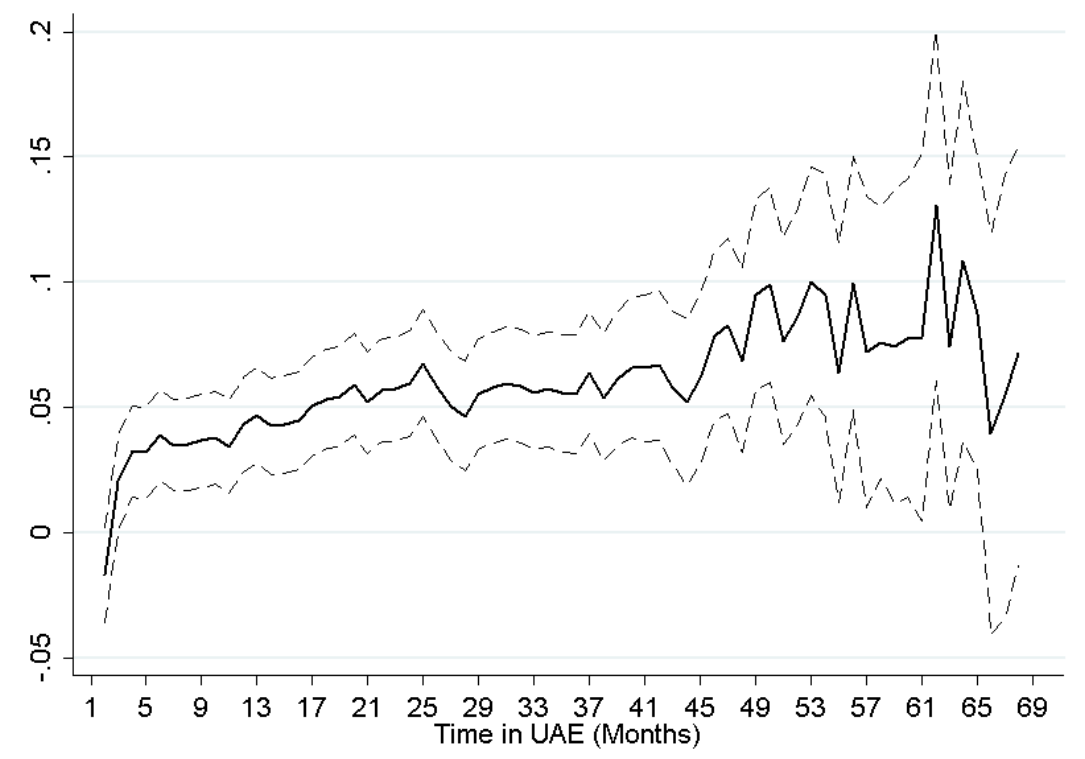

(b) Log Remittances

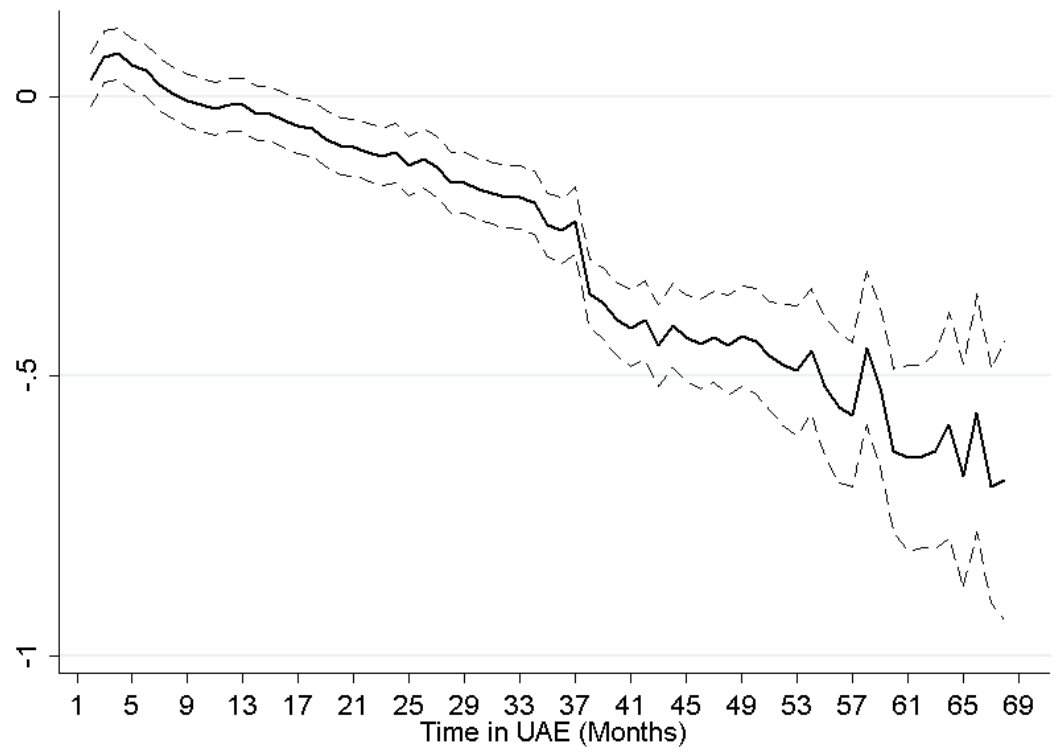

Notes: The estimated coefficients associated with each month of time in the UAE is given by the solid line. The regression includes individual fixed effects, year indicators and month indicators. The omitted category in the regressions is the first month of work. The $95 \%$ confidence interval is given by the dashed lines. The estimation sample is restricted to time in the UAE of up to 70 months. 
Table 1: Summary Statistics

\begin{tabular}{|c|c|c|c|c|c|}
\hline & $\begin{array}{c}\text { Remittance } \\
\text { Only } \\
\text { Sample } \\
(1)\end{array}$ & $\begin{array}{c}\text { Earnings } \\
\text { Only } \\
\text { Sample } \\
(2)\end{array}$ & $\begin{array}{c}\text { Merged } \\
\text { Sample } \\
(3)\end{array}$ & $\begin{array}{c}\text { Unobserved } \\
\text { Earning as } \\
\text { Zero } \\
(4)\end{array}$ & $\begin{array}{c}\text { Unobserved } \\
\text { Remittance } \\
\text { as Zero } \\
(5)\end{array}$ \\
\hline \multicolumn{6}{|c|}{ Panel A: Financial Firm Variables } \\
\hline Remittances & $\begin{array}{c}2668.2 \\
(3069.5)\end{array}$ & & $\begin{array}{c}1327.2 \\
(1383.5)\end{array}$ & $\begin{array}{c}1326.2 \\
(1386.0)\end{array}$ & $\begin{array}{c}912.0 \\
(1305.4)\end{array}$ \\
\hline India & $\begin{array}{c}0.501 \\
(0.500)\end{array}$ & $\begin{array}{c}0.487 \\
(0.500)\end{array}$ & $\begin{array}{c}0.496 \\
(0.500)\end{array}$ & $\begin{array}{c}0.495 \\
(0.500)\end{array}$ & $\begin{array}{c}0.543 \\
(0.498)\end{array}$ \\
\hline Monthly Earnings & & $\begin{array}{c}1433.7 \\
(1305.6)\end{array}$ & $\begin{array}{c}1559.8 \\
(1214.9)\end{array}$ & $\begin{array}{c}1528.6 \\
(1222.3)\end{array}$ & $\begin{array}{c}1474.1 \\
(1150.8)\end{array}$ \\
\hline Age & & $\begin{array}{c}35.52 \\
(8.722)\end{array}$ & $\begin{array}{c}36.31 \\
(8.734)\end{array}$ & $\begin{array}{c}36.30 \\
(8.729)\end{array}$ & $\begin{array}{c}36.05 \\
(8.617)\end{array}$ \\
\hline Male & & $\begin{array}{c}0.991 \\
(0.0926)\end{array}$ & $\begin{array}{c}0.992 \\
(0.0895)\end{array}$ & $\begin{array}{c}0.992 \\
(0.0898)\end{array}$ & $\begin{array}{c}0.993 \\
(0.0845)\end{array}$ \\
\hline Observations & 34997684 & 6521954 & 553647 & 564968 & 927158 \\
\hline \multicolumn{6}{|c|}{ Panel B: Constructed Financial Firm Variable } \\
\hline Outdoor Occupation & & $\begin{array}{c}0.446 \\
(0.497)\end{array}$ & $\begin{array}{c}0.516 \\
(0.500)\end{array}$ & $\begin{array}{c}0.518 \\
(0.500)\end{array}$ & $\begin{array}{c}0.547 \\
(0.498)\end{array}$ \\
\hline Observations & & 2944509 & 269761 & 277017 & 467419 \\
\hline Time in UAE & & $\begin{array}{c}2.477 \\
(1.858)\end{array}$ & $\begin{array}{c}2.109 \\
(1.618)\end{array}$ & $\begin{array}{c}2.109 \\
(1.618)\end{array}$ & $\begin{array}{c}2.134 \\
(1.620)\end{array}$ \\
\hline Observations & & 5267546 & 537836 & 548226 & 895480 \\
\hline \multicolumn{6}{|c|}{ Panel C: MOL Variables } \\
\hline Muslim & & $\begin{array}{c}0.340 \\
(0.474)\end{array}$ & $\begin{array}{c}0.323 \\
(0.468)\end{array}$ & $\begin{array}{c}0.324 \\
(0.468)\end{array}$ & $\begin{array}{c}0.313 \\
(0.464)\end{array}$ \\
\hline High Education & & $\begin{array}{c}0.388 \\
(0.487)\end{array}$ & $\begin{array}{c}0.404 \\
(0.491)\end{array}$ & $\begin{array}{c}0.404 \\
(0.491)\end{array}$ & $\begin{array}{c}0.382 \\
(0.486)\end{array}$ \\
\hline Observations & & 5351152 & 551052 & 562362 & 922782 \\
\hline \multicolumn{6}{|c|}{ Panel D: Within Contract Coefficient of Variation } \\
\hline CV Earnings & & $\begin{array}{c}0.278 \\
(0.195)\end{array}$ & $\begin{array}{c}0.295 \\
(0.173)\end{array}$ & $\begin{array}{c}0.304 \\
(0.179)\end{array}$ & $\begin{array}{c}0.295 \\
(0.173)\end{array}$ \\
\hline CV Remittances & & & $\begin{array}{c}0.700 \\
(0.478)\end{array}$ & $\begin{array}{c}0.700 \\
(0.478)\end{array}$ & $\begin{array}{l}1.124 \\
(0.583)\end{array}$ \\
\hline Observations & & 547572 & 112357 & 112342 & 112668 \\
\hline
\end{tabular}

Notes: Standard deviations in parentheses. Remittances and earnings are in real 2007 dirham. 
Table 2: Fixed Effects Relationship between Log Earnings and Log Remittances

\begin{tabular}{|c|c|c|}
\hline & $(1)$ & $(2)$ \\
\hline \multicolumn{3}{|c|}{ Panel A: Merged Sample } \\
\hline \multirow[t]{2}{*}{ Log(Earnings) } & $0.325^{* *}$ & $0.326^{* *}$ \\
\hline & {$[0.005]$} & {$[0.005]$} \\
\hline Worker Controls & No & Yes \\
\hline Observations & 573132 & 543655 \\
\hline Adjusted $R^{2}$ & 0.404 & 0.404 \\
\hline \multicolumn{3}{|c|}{ Panel B: Unobserved Earnings as Zero } \\
\hline \multirow{2}{*}{ Log(Earnings) } & $0.046^{* *}$ & $0.046^{* *}$ \\
\hline & {$[0.002]$} & {$[0.002]$} \\
\hline Worker Controls & No & Yes \\
\hline Observations & 584976 & 554688 \\
\hline Adjusted $R^{2}$ & 0.391 & 0.391 \\
\hline \multicolumn{3}{|c|}{ Panel C: Unobserved Remittances as Zero } \\
\hline \multirow[t]{2}{*}{ Log(Earnings) } & $1.027^{* *}$ & $1.028^{* *}$ \\
\hline & {$[0.012]$} & {$[0.012]$} \\
\hline Worker Controls & No & Yes \\
\hline Observations & 957764 & 904375 \\
\hline Adjusted $R^{2}$ & 0.176 & 0.175 \\
\hline
\end{tabular}

Notes: Robust standard errors clustered by individual in parentheses. $+,{ }^{*},{ }^{* *}$ denote significance at the $10 \%, 5 \%$ and $1 \%$ levels, respectively. The regressions include individual fixed effects, year fixed effects and a constant term.

Table 3: Effects of Ramadan on Income and Remittances

\begin{tabular}{lcccc}
\hline \hline & \multicolumn{2}{c}{ Log Earnings } & \multicolumn{2}{c}{ Log Remittances } \\
& Full Sample & All Mons & Full Sample & All Mons \\
& $(1)$ & $(2)$ & $(3)$ & $(4)$ \\
\hline Panel A: Ramadan Effects & & & & \\
Days Ramadan/10 & $-0.012^{* *}$ & $-0.010^{* *}$ & $-0.023^{* *}$ & $-0.024^{* *}$ \\
& {$[0.001]$} & {$[0.001]$} & {$[0.002]$} & {$[0.002]$} \\
Observations & 573132 & 359908 & 573132 & 359908 \\
Adjusted $R^{2}$ & 0.714 & 0.704 & 0.392 & 0.360 \\
\hline Panel B: Ramadan $\times$ Muslim Effects & & & \\
Days Ramadan/10 & $-0.004^{*}$ & -0.002 & $-0.015^{* *}$ & $-0.018^{* *}$ \\
& {$[0.002]$} & {$[0.002]$} & {$[0.004]$} & {$[0.004]$} \\
Muslim $\times$ Ramadan Days/10 & $-0.020^{* *}$ & $-0.019^{* *}$ & $-0.020^{* *}$ & $-0.019^{* *}$ \\
& {$[0.003]$} & {$[0.003]$} & {$[0.006]$} & {$[0.007]$} \\
Observations & 233204 & 159700 & 233204 & 159700 \\
Adjusted $R^{2}$ & 0.720 & 0.708 & 0.392 & 0.363 \\
\hline \hline
\end{tabular}

Notes: Robust standard errors clustered by individual in parentheses. $+,{ }^{*},{ }^{* *}$ denote significance at the $10 \%, 5 \%$ and $1 \%$ levels, respectively. Regressions include year fixed effects, individual fixed effects and a constant term. 
Table 4: Effects of Ramadan on Income and Remittances by Muslim Share in Country of Origin

\begin{tabular}{lcc}
\hline \hline & Log Earnings & Log Remittances \\
& $(1)$ & $(2)$ \\
\hline Ramadan & $-0.011^{*}$ & $-0.031^{* *}$ \\
Ramadan X Muslim Share in Origin Country & {$[0.005]$} & {$[0.012]$} \\
& -0.001 & -0.038 \\
Observations & {$[0.019]$} & {$[0.052]$} \\
Adjusted $R^{2}$ & 129283 & 129283 \\
\hline \hline
\end{tabular}

Notes: Sample restricted to non-Muslim workers. Robust standard errors clustered by individual in parentheses. $+,{ }^{*},{ }^{* *}$ denote significance at the $10 \%, 5 \%$ and $1 \%$ levels, respectively. Regressions include year fixed effects, individual fixed effects and a constant term.

Table 5: Impact of Weather Shocks on Income and Remittances

\begin{tabular}{|c|c|c|c|c|}
\hline & \multicolumn{2}{|c|}{ Log Earnings } & \multicolumn{2}{|c|}{ Log Remittances } \\
\hline & (1) & $(2)$ & $(3)$ & $(4)$ \\
\hline \multicolumn{5}{|c|}{ Panel A: Rainfall Shocks } \\
\hline Precipitation & $\begin{array}{c}-0.356^{* *} \\
{[0.034]}\end{array}$ & $\begin{array}{c}-0.305^{* *} \\
{[0.067]}\end{array}$ & $\begin{array}{c}-0.266^{* *} \\
{[0.078]}\end{array}$ & $\begin{array}{c}-0.364^{*} \\
{[0.155]}\end{array}$ \\
\hline Precipitation $\times$ Outdoor & & $\begin{array}{c}-0.170^{*} \\
{[0.078]}\end{array}$ & & $\begin{array}{l}-0.005 \\
{[0.183]}\end{array}$ \\
\hline Observations & 563312 & 267432 & 563312 & 267432 \\
\hline Adjusted $R^{2}$ & 0.715 & 0.698 & 0.392 & 0.371 \\
\hline Panel B: Heat Shocks & & & & \\
\hline Maximum Temperature & $\begin{array}{c}-0.003^{* *} \\
{[0.001]}\end{array}$ & $\begin{array}{c}-0.003^{* *} \\
{[0.001]}\end{array}$ & $\begin{array}{c}-0.010^{* *} \\
{[0.001]}\end{array}$ & $\begin{array}{c}-0.017^{* *} \\
{[0.002]}\end{array}$ \\
\hline Temperature $\times$ Outdoor & & $\begin{array}{c}-0.001^{* *} \\
{[0.000]}\end{array}$ & & $\begin{array}{c}-0.001^{* *} \\
{[0.000]}\end{array}$ \\
\hline Observations & 563312 & 267432 & 563312 & 267432 \\
\hline Adjusted $\mathrm{R}^{2}$ & 0.714 & 0.698 & 0.392 & 0.372 \\
\hline Mean of Outcome & 7.172 & 7.160 & 6.992 & 6.958 \\
\hline Standard Deviation & 0.598 & 0.588 & 0.956 & 0.962 \\
\hline
\end{tabular}

Notes: Robust standard errors clustered by individual in parentheses. +, *, ** denote significance at the $10 \%, 5 \%$ and $1 \%$ levels, respectively. Regressions include fixed effects for year, city-month and individual and a constant term. 
Table 6: Impact of a Labor Reform on Income and Remittances

\begin{tabular}{lcc}
\hline \hline & $\begin{array}{c}\text { Log Earnings } \\
(1)\end{array}$ & $\begin{array}{c}\text { Log Remittances } \\
(2)\end{array}$ \\
\hline Post Reform X Post Expiration & $0.040+$ & $0.117^{*}$ \\
Post Reform X Contract Expiration & {$[0.024]$} & {$[0.056]$} \\
& $0.035^{* *}$ & $0.065^{*}$ \\
Observations & {$[0.013]$} & {$[0.033]$} \\
Adjusted R & 56057 & 56057 \\
\hline \hline
\end{tabular}

Notes: Robust standard errors clustered by individual in parentheses. $+,{ }^{*},{ }^{* *}$ denote significance at the $10 \%, 5 \%$ and $1 \%$ levels, respectively. Regressions include year-month fixed effects, individual fixed effects and a constant term.

Table 7: Estimates of Time in the UAE on Income and Remittances

\begin{tabular}{|c|c|c|c|c|}
\hline & \multicolumn{2}{|c|}{ Log Earnings } & \multicolumn{2}{|c|}{ Log Remittances } \\
\hline & (1) & $(2)$ & $(3)$ & $(4)$ \\
\hline \multicolumn{5}{|c|}{ Panel A: Full Sample } \\
\hline \multirow{2}{*}{ Time in UAE } & $0.017^{* *}$ & $0.018^{* *}$ & $-0.096^{* *}$ & $-0.086^{* *}$ \\
\hline & {$[0.002]$} & {$[0.003]$} & {$[0.005]$} & {$[0.007]$} \\
\hline \multirow[t]{2}{*}{ Time in $\mathrm{UAE}^{2}$} & & -0.000 & & $-0.002^{*}$ \\
\hline & & {$[0.000]$} & & {$[0.001]$} \\
\hline Observations & 543903 & 543903 & 543903 & 543903 \\
\hline Adjusted $\mathrm{R}^{2}$ & 0.719 & 0.719 & 0.400 & 0.400 \\
\hline \multicolumn{5}{|c|}{ Panel B: First Contract Sample } \\
\hline \multirow[t]{2}{*}{ Time in UAE } & $0.018^{* *}$ & $0.050^{* *}$ & $-0.079^{* *}$ & $-0.055^{* *}$ \\
\hline & {$[0.003]$} & {$[0.005]$} & {$[0.006]$} & {$[0.011]$} \\
\hline \multirow[t]{2}{*}{ Time in $\mathrm{UAE}^{2}$} & & $-0.008^{* *}$ & & $-0.006^{* *}$ \\
\hline & & {$[0.001]$} & & {$[0.002]$} \\
\hline Observations & 496266 & 496266 & 496266 & 496266 \\
\hline Adjusted $\mathrm{R}^{2}$ & 0.727 & 0.727 & 0.404 & 0.404 \\
\hline
\end{tabular}

Notes: Robust standard errors clustered by individual in parentheses. $+,{ }^{*}, * *$ denote significance at the $10 \%, 5 \%$ and $1 \%$ levels, respectively. Regressions include year fixed effects, month fixed effects, individual fixed effects and a constant term. 


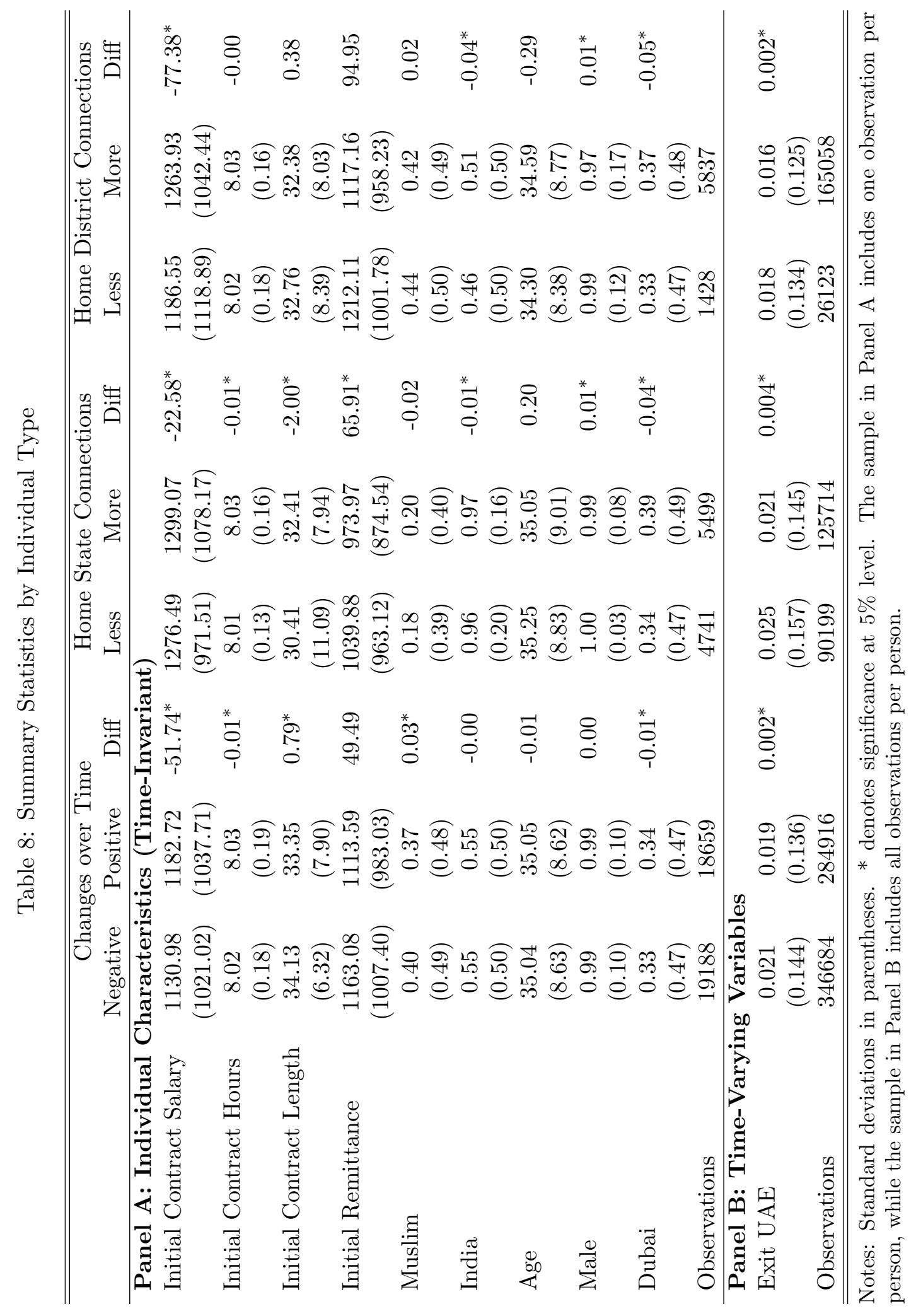


Table 9: Asymmetries in the Effects of Time in UAE on Income and Remittances

\begin{tabular}{lcccc}
\hline \hline & \multicolumn{2}{c}{ Log Earnings } & \multicolumn{2}{c}{ Log Remittances } \\
& $(1)$ & $(2)$ & $(3)$ & $(4)$ \\
\hline Time X Neg_Changes & $-0.096^{* *}$ & $-0.103^{* *}$ & $-0.106^{* *}$ & $-0.106^{* *}$ \\
& {$[0.003]$} & {$[0.013]$} & {$[0.006]$} & {$[0.024]$} \\
Time X Pos_Changes & $0.114^{* *}$ & $0.108^{* *}$ & $-0.016^{* *}$ & -0.014 \\
& {$[0.002]$} & {$[0.013]$} & {$[0.006]$} & {$[0.024]$} \\
Worker Controls & No & Yes & No & Yes \\
Observations & 535254 & 507812 & 535254 & 507812 \\
Adjusted $R^{2}$ & 0.728 & 0.730 & 0.408 & 0.409 \\
\hline \hline
\end{tabular}

Notes: Robust standard errors clustered by individual in parentheses. + , $*$, ** denote significance at the $10 \%, 5 \%$ and $1 \%$ levels, respectively. Time in UAE refers to the number of months that they have been in the UAE divided by 10 . Regressions include year indicators and month indicators, individual fixed effects and a constant term.

Table 10: Asymmetries in the Effects of Time in UAE and Home Connections

\begin{tabular}{|c|c|c|c|c|}
\hline \multirow[b]{2}{*}{ Home Connections: } & \multicolumn{2}{|c|}{ Log Earnings } & \multicolumn{2}{|c|}{ Log Remittances } \\
\hline & $\begin{array}{l}\text { Less } \\
(1)\end{array}$ & $\begin{array}{l}\text { More } \\
(2)\end{array}$ & $\begin{array}{l}\text { Less } \\
(3)\end{array}$ & $\begin{array}{l}\text { More } \\
(4)\end{array}$ \\
\hline \multicolumn{5}{|c|}{ Panel A: State-Level Home Connections } \\
\hline Time X Neg_Changes & $\begin{array}{c}-0.110^{* *} \\
{[0.007]}\end{array}$ & $\begin{array}{c}-0.106^{* *} \\
{[0.008]}\end{array}$ & $\begin{array}{c}-0.088^{* *} \\
{[0.017]}\end{array}$ & $\begin{array}{c}-0.056^{* *} \\
{[0.021]}\end{array}$ \\
\hline Time X Pos_Changes & $\begin{array}{c}0.075^{* *} \\
{[0.007]}\end{array}$ & $\begin{array}{c}0.106^{* *} \\
{[0.008]}\end{array}$ & $\begin{array}{c}0.002 \\
{[0.017]}\end{array}$ & $\begin{array}{l}0.045^{*} \\
{[0.020]}\end{array}$ \\
\hline Observations & 64929 & 65014 & 64929 & 65014 \\
\hline Adjusted $R^{2}$ & 0.043 & 0.043 & 0.042 & 0.031 \\
\hline \multicolumn{5}{|c|}{ Panel B: District-Level Home Connections } \\
\hline Time X Neg_Changes & $\begin{array}{c}-0.080^{* *} \\
{[0.007]}\end{array}$ & $\begin{array}{c}-0.109^{* *} \\
{[0.010]}\end{array}$ & $\begin{array}{c}-0.173^{* *} \\
{[0.018]}\end{array}$ & $\begin{array}{c}-0.096^{* *} \\
{[0.026]}\end{array}$ \\
\hline Time X Pos_Changes & $\begin{array}{c}0.115^{* *} \\
{[0.006]}\end{array}$ & $\begin{array}{c}0.127^{* *} \\
{[0.010]}\end{array}$ & $\begin{array}{c}-0.072^{* *} \\
{[0.018]}\end{array}$ & $\begin{array}{c}-0.036 \\
{[0.025]}\end{array}$ \\
\hline Observations & 47495 & 43519 & 46791 & 42480 \\
\hline Adjusted $\mathrm{R}^{2}$ & 0.043 & 0.042 & 0.011 & 0.004 \\
\hline
\end{tabular}

Notes: Robust standard errors clustered by individual in parentheses. +, $*$, ** denote significance at the $10 \%, 5 \%$ and $1 \%$ levels, respectively. Time in UAE refers to the number of months that they have been in the UAE divided by 10. Regressions include year indicators, month indicators, individual fixed effects and a constant term. 
Table 11: Impact of Selection on the Relationship between Earnings and Remittances

\begin{tabular}{lcccc}
\hline \hline & \multicolumn{2}{c}{ Log Remittances High } & \multicolumn{2}{c}{ Log Remittances Low } \\
& $(1)$ & $(2)$ & $(3)$ & $(4)$ \\
\hline Log Earnings High & $0.391^{* *}$ & & $0.248^{* *}$ & \\
& {$[0.004]$} & & {$[0.004]$} & \\
Log Earnings Low & & $0.203^{* *}$ & & $0.383^{* *}$ \\
& & {$[0.004]$} & & {$[0.004]$} \\
Observations & 771635 & 771635 & 771635 & 771635 \\
Adjusted $R^{2}$ & 0.435 & 0.423 & 0.428 & 0.439 \\
\hline \hline
\end{tabular}

Notes: Robust standard errors clustered by individual in parentheses.,$+{ }^{*}$, ** denote significance at the $10 \%, 5 \%$ and $1 \%$ levels, respectively. Regressions include year fixed effects, individual fixed effects and a constant term.

Table 12: Impact of Selection on the Estimates of Time in the UAE

\begin{tabular}{lcccc}
\hline \hline & \multicolumn{2}{c}{ Log Earnings } & \multicolumn{2}{c}{ Log Remittances } \\
& High & Low & High & Low \\
& $(1)$ & $(2)$ & $(3)$ & $(4)$ \\
\hline Panel A: Time in UAE & & & \\
Time in UAE & $0.014^{* *}$ & $0.005+$ & $-0.016^{* *}$ & $-0.032^{* *}$ \\
& {$[0.003]$} & {$[0.003]$} & {$[0.005]$} & {$[0.006]$} \\
Observations & 771642 & 771642 & 771642 & 771642 \\
Adjusted $R^{2}$ & 0.701 & 0.716 & 0.432 & 0.419 \\
\hline Panel B: Asymmetric Effect & & & \\
Time X Neg_Changes & $-0.102^{* *}$ & $-0.084^{* *}$ & $-0.085^{* *}$ & $-0.057^{* *}$ \\
& {$[0.003]$} & {$[0.003]$} & {$[0.006]$} & {$[0.006]$} \\
Time X Pos_Changes & $0.074^{* *}$ & $0.071^{* *}$ & -0.010 & -0.004 \\
& {$[0.003]$} & {$[0.003]$} & {$[0.006]$} & {$[0.006]$} \\
Observations & 604021 & 604021 & 604021 & 604021 \\
Adjusted $R^{2}$ & 0.705 & 0.721 & 0.434 & 0.419 \\
\hline \hline
\end{tabular}

Notes: Robust standard errors clustered by individual in parentheses. +, $*$, ${ }^{* *}$ denote significance at the $10 \%, 5 \%$ and $1 \%$ levels, respectively. Time in UAE refers to the number of months that they have been in the UAE divided by 10. Regressions include year indicators, month indicators, individual fixed effects and a constant term. 


\section{ONLINE APPENDIX - FOR ONLINE PUBLICATION ONLY}

\section{A Theoretical Appendix}

\section{A.1 Models of Altruism}

Models of altruistic remittances posit that migrants get utility from the consumption of household members at home. We present a model that adapts Lucas and Stark (1985) and Rapoport and Docquier (2006). Consider a migrant who maximizes his own utility with respect to the amount remitted:

$$
u_{m}=u\left[c_{m}(w-r), a_{h} u_{h}\left(c_{h}\right)\right]
$$

where the migrant's consumption, $c_{m}$, depends on $w$, the migrant's earnings in the host country, less $r$, the amount remitted to the household at home. The altruism weight attached to the household at home is given by $a_{h}$.

Consumption of the household at home is given by $c_{h}=c(y+r)$ where $y$ is the earnings of household members at home. A migrant chooses a level of $r$ to maximize his utility, and two predictions result: $\partial r / \partial w>0$ and $\partial r / \partial y<0$. Given our data, one testable implication of the model of altruism is that remittances should rise and fall with the earnings of the migrant. ${ }^{38}$ Under a model of pure altruism, remittances should move with income regardless of whether income is observable by others or not.

\section{A.2 Models of Consumption Smoothing with Altruism}

Models of altruism suggest that migrants treat the consumption of household members at home similarly to their own consumption in the host country (adjusted by an altruism weight). Under the permanent income hypothesis, migrants should attempt to smooth the marginal utility of consumption over short-run fluctuations in income (Friedman 1957, Carroll 2001). ${ }^{39}$ The key empirical predictions of this model are that consumption should respond to unpredictable income shocks but not to predictable, transitory income changes. If remittances finance consumption of households at home, altruistic migrants should smooth their remittances over anticipated fluctuations in earnings.

\section{A.3 Exchange Motives}

Exchange-based models of remittances consider remittances as a method whereby migrants pay for some type of service at home, such as taking care of the migrants' children or elderly parents. Similarly, an exchange-based model may be such that remittances represent a repayment for the loans used to finance the migrant's international move or the migrant's human capital investments. ${ }^{40}$

We present an outline from Rapoport and Docquier (2006) of the Cox's (1987) exchange motive model of remittance where migrants (and households at home) have no altruistic motives and migrants want to buy a service, $X$. The utility function of the migrant, denoted by $m$, and of the household, denoted by $h$, is given by $V^{i}\left(C^{i}, X\right)$ where $i=m, h$. The migrant's utility is increasing in $X$ at

\footnotetext{
${ }^{38}$ The other interesting implication is that remittances should fall with an increase in income of the household at home, but we do not have the data to explore this.

${ }^{39}$ The model relies on a number of assumptions, including that credit markets work perfectly such that individuals can borrow and lend at the same interest rate and quadratic preferences. Common extensions to the standard model relax some of these assumptions to allow for a failure of the credit market and buffer stock savings (Carroll 2001). We do not consider this idea in this paper because we do not observe cash-in-hand.

${ }^{40}$ While the model below would not apply exactly to a loan repayment, migrants want to remit and pay down the debt when they experience positive income fluctuations and are able to pay less of the debt when they experience negative income fluctuations. Again the observability of income would not matter.
} 
a decreasing rate while the household's utility is decreasing in $X$ at an increasing rate. The latter assumes that it is costly for the household to provide $X$ and there is increasing disutility from this effort. For the migrant to participate in the exchange, the maximal amount that he is willing to remit, denoted by $X$, is such that: $V^{m}\left(I^{m}-R^{\max } ; X\right)=V^{m}\left(I^{m} ; 0\right)$. Applying the implicit function theorem yields the result that $R^{\max }$ increases with the migrant's income. Like with the model of altruism, the exchange model predicts that remittances should increase with the migrant's income but that the observability of that income should not matter. ${ }^{41}$

\section{B Data Appendix}

\section{B.1 Merging Payroll Disbursals and Remittance Transactions}

We received hundreds of text files that represented two separate data sets on remittance transactions and payroll disbursals. The salary data is at the year-month level with occasional cases (less than $5 \%$ ) in which the same individual receives multiple payments in a single calendar month. We aggregate those numbers to the total earned in that month. The remittance data is a transactions level data set and individuals can choose to remit at any frequency that they desire. However, the fee associated with remittances is a flat rate per remittance. The mean and median number of remittances per month in the data is one. Thus, in cases where there is more than one remittance in a calendar month, we aggregate those up to the monthly level to match with the salary disbursal data. Thus, the final data set is a panel of individuals at the monthly level.

The identifiers used in the salary data set are generated by the firm and called customer registration numbers. These numbers are also available for some observations in the remittance data, and we begin by linking remittance transactions and earnings disbursals using the employee registration number. Of the observations that remain unlinked, we next use the labor card identifier, which is a government issued identifier that is unique for every worker-contract, to match remittances and earnings. While the labor card identifer is not directly associated with earnings disbursals, we are able to link $95 \%$ of the employee registration numbers in the salary disbursal data set to an employees data set that contains their labor card identification number as well as some characteristics of the worker, such as age, country of origin and gender.

\section{B.2 Merging the Payroll and Remittance Data with the MOL Data}

Both the MOL data on labor contracts of migrant workers and the payroll processing records contain a UAE government issued identifier called the labor card id number. This numeric identifier is associated with each individual's contract. When workers change employer or sign a new contract with an existing employer, they receive a new labor card and a new labor card id number. We use this identifier to match the two data sets. We lose 107,698 individuals in the payroll processing data set who have missing, non-numeric or incomplete identifiers, driven by the fact that some individuals in the payroll processing data set do not provide their labor card id. Some individuals provide the company with their passport number or a driver's license, but the labor card id is used in the vast majority of cases. We are able to match 553,375 individuals in the payroll processing data with their contract information in the MOL data set. There are 25,883 individuals present in the payroll processing data that are not matched into the MOL data set. This reflects the fact that some migrant workers, including domestic workers and those working in the freezone areas of the UAE, fall under the jurisdiction of the Ministry of the Interior rather than the MOL.

\footnotetext{
${ }^{41}$ The exchange model has a distinct prediction from altruism; under the exchange model, remittances can increase with the incomes of the households at home.
} 
Appendix Table A.1: Impact of Lags and Leads of Earnings on Log Remittances

\begin{tabular}{|c|c|c|c|c|c|}
\hline & (1) & $(2)$ & (3) & (4) & $(5)$ \\
\hline \multirow[t]{2}{*}{ Log(Earnings) } & $0.323^{* *}$ & $0.324^{* *}$ & $0.334^{* *}$ & $0.339^{* *}$ & $0.335^{* *}$ \\
\hline & {$[0.005]$} & {$[0.006]$} & {$[0.005]$} & {$[0.006]$} & {$[0.007]$} \\
\hline \multirow[t]{2}{*}{ Lag1 Log(Earnings) } & $0.044^{* *}$ & $0.046^{* *}$ & & & $0.051^{* *}$ \\
\hline & {$[0.004]$} & {$[0.005]$} & & & {$[0.005]$} \\
\hline \multirow[t]{2}{*}{ Lag2 Log(Earnings) } & & $0.023^{* *}$ & & & $0.028 * *$ \\
\hline & & {$[0.005]$} & & & {$[0.005]$} \\
\hline \multirow[t]{2}{*}{ Lag3 Log(Earnings) } & & 0.004 & & & $0.009+$ \\
\hline & & {$[0.005]$} & & & {$[0.005]$} \\
\hline \multirow[t]{2}{*}{ Lead1 Log(Earnings) } & & & $-0.028^{* *}$ & $-0.031^{* *}$ & $-0.033^{* *}$ \\
\hline & & & {$[0.004]$} & {$[0.005]$} & {$[0.006]$} \\
\hline \multirow[t]{2}{*}{ Lead2 Log(Earnings) } & & & & $0.018^{* *}$ & $0.023^{* *}$ \\
\hline & & & & {$[0.004]$} & {$[0.005]$} \\
\hline \multirow[t]{2}{*}{ Lead3 Log(Earnings) } & & & & $0.007+$ & $0.011^{*}$ \\
\hline & & & & {$[0.004]$} & {$[0.005]$} \\
\hline Observations & 523609 & 428683 & 540938 & 480236 & 363033 \\
\hline Adjusted $R^{2}$ & 0.404 & 0.403 & 0.404 & 0.399 & 0.396 \\
\hline
\end{tabular}

Notes: Robust standard errors clustered by individual in parentheses. $+,{ }^{*},{ }^{* *}$ denote significance at the $10 \%, 5 \%$ and $1 \%$ levels, respectively. The regressions include individual fixed effects, year fixed effects and a constant term. 
Appendix Table A.2: Effects of Seasonalities on Income and Remittances

\begin{tabular}{|c|c|c|c|c|}
\hline & \multicolumn{2}{|c|}{ Log Earnings } & \multicolumn{2}{|c|}{ Log Remittances } \\
\hline & $\begin{array}{c}\text { Full Sample } \\
\text { (1) }\end{array}$ & $\begin{array}{l}\text { All Months } \\
(2)\end{array}$ & $\begin{array}{c}\text { Full Sample } \\
\text { (3) }\end{array}$ & $\begin{array}{l}\text { All Months } \\
\text { (4) }\end{array}$ \\
\hline \multirow[t]{2}{*}{ February } & $-0.015^{* *}$ & $-0.012^{* *}$ & -0.007 & -0.001 \\
\hline & {$[0.002]$} & {$[0.003]$} & {$[0.006]$} & {$[0.007]$} \\
\hline \multirow[t]{2}{*}{ March } & $0.006^{*}$ & -0.001 & 0.005 & 0.003 \\
\hline & {$[0.003]$} & {$[0.003]$} & {$[0.006]$} & {$[0.007]$} \\
\hline \multirow[t]{2}{*}{ April } & 0.003 & $0.006^{*}$ & $-0.012+$ & -0.005 \\
\hline & {$[0.003]$} & {$[0.003]$} & {$[0.006]$} & {$[0.007]$} \\
\hline \multirow[t]{2}{*}{ May } & $-0.008^{* *}$ & $-0.008^{*}$ & $0.014^{*}$ & $0.022^{* *}$ \\
\hline & {$[0.003]$} & {$[0.003]$} & {$[0.006]$} & {$[0.008]$} \\
\hline \multirow[t]{2}{*}{ June } & $-0.017^{* *}$ & $-0.018^{* *}$ & $-0.015^{*}$ & -0.006 \\
\hline & {$[0.003]$} & {$[0.003]$} & {$[0.006]$} & {$[0.008]$} \\
\hline \multirow[t]{2}{*}{ July } & -0.002 & $-0.005+$ & $-0.033^{* *}$ & $-0.030^{* *}$ \\
\hline & {$[0.003]$} & {$[0.003]$} & {$[0.006]$} & {$[0.007]$} \\
\hline \multirow[t]{2}{*}{ August } & $0.006^{*}$ & 0.004 & $-0.030^{* *}$ & $-0.029 * *$ \\
\hline & {$[0.003]$} & {$[0.003]$} & {$[0.006]$} & {$[0.007]$} \\
\hline \multirow[t]{2}{*}{ September } & $-0.043^{* *}$ & $-0.040 * *$ & $-0.061^{* *}$ & $-0.059 * *$ \\
\hline & {$[0.003]$} & {$[0.003]$} & {$[0.006]$} & {$[0.007]$} \\
\hline \multirow[t]{2}{*}{ October } & $-0.038^{* *}$ & $-0.043^{* *}$ & $-0.029^{* *}$ & $-0.028^{* *}$ \\
\hline & {$[0.003]$} & {$[0.003]$} & {$[0.006]$} & {$[0.007]$} \\
\hline \multirow[t]{2}{*}{ November } & $-0.016^{* *}$ & $-0.022^{* *}$ & $-0.022^{* *}$ & $-0.020 * *$ \\
\hline & {$[0.003]$} & {$[0.003]$} & {$[0.006]$} & {$[0.007]$} \\
\hline \multirow[t]{2}{*}{ December } & $0.018^{* *}$ & $0.017^{* *}$ & 0.003 & 0.007 \\
\hline & {$[0.003]$} & {$[0.003]$} & {$[0.006]$} & {$[0.007]$} \\
\hline Observations & 573132 & 359908 & 573132 & 359908 \\
\hline Adjusted $R^{2}$ & 0.715 & 0.704 & 0.391 & 0.360 \\
\hline
\end{tabular}

Notes: Robust standard errors clustered by individual in parentheses. +, ${ }^{*}$, ** denote significance at the $10 \%, 5 \%$ and $1 \%$ levels, respectively. Regressions include year fixed effects, individual fixed effects and a constant term. 
Appendix Table A.3: Estimates of the Impact of Weather (in Days) on Income and Remittances

\begin{tabular}{lcc}
\hline \hline & $\begin{array}{c}\text { Log Earnings } \\
(1)\end{array}$ & $\begin{array}{c}\text { Log Remittances } \\
(2)\end{array}$ \\
\hline Panel A: Rainfall Shocks & & \\
Days Any Precipitation & $-0.003^{* * *}$ & $-0.005^{* * *}$ \\
& {$[0.000]$} & {$[0.001]$} \\
Observations & 563312 & 563312 \\
Adjusted $R^{2}$ & 0.714 & 0.392 \\
\hline Panel B: Heat Shocks & & \\
Days Max Temp 70-80 & -0.000 & $-0.005^{* *}$ \\
& {$[0.001]$} & {$[0.002]$} \\
Days Max Temp 80-90 & -0.001 & $-0.007^{* *}$ \\
& {$[0.001]$} & {$[0.002]$} \\
Days Max Temp 90-100 & -0.001 & $-0.011^{* *}$ \\
& {$[0.001]$} & {$[0.002]$} \\
Days Max Temp 100-110 & -0.001 & $-0.011^{* *}$ \\
& {$[0.001]$} & {$[0.002]$} \\
Days Max Temp Over 110 & $-0.003^{* *}$ & $-0.015^{* *}$ \\
Observations & {$[0.001]$} & {$[0.002]$} \\
Adjusted $R^{2}$ & 563312 & 563312 \\
\hline \hline
\end{tabular}

Notes: Robust standard errors clustered by individual in parentheses. $+,{ }^{*}, * *$ denote significance at the $10 \%, 5 \%$ and $1 \%$ levels, respectively. Regressions include fixed effects for year, city-month and individual and a constant term.

Appendix Table A.4: Effects of Ramadan on Income and Remittances

\begin{tabular}{lcccc}
\hline \hline & \multicolumn{2}{c}{ Log Earnings } & \multicolumn{2}{c}{ Log Remittances } \\
& Full Sample & All Mons & Full Sample & All Mons \\
& $(1)$ & $(2)$ & $(3)$ & $(4)$ \\
\hline Panel A: Ramadan Effects & & & \\
Ramadan & $-0.029^{* *}$ & $-0.026^{* *}$ & $-0.060^{* *}$ & $-0.065^{* *}$ \\
& {$[0.002]$} & {$[0.002]$} & {$[0.004]$} & {$[0.005]$} \\
Observations & 573132 & 359908 & 573132 & 359908 \\
Adjusted $R^{2}$ & 0.715 & 0.704 & 0.392 & 0.361 \\
\hline Panel B: Ramadan $\times$ Muslim Effects & & \\
Ramadan & $-0.013^{* *}$ & $-0.011^{* *}$ & $-0.046^{* *}$ & $-0.053^{* *}$ \\
& {$[0.003]$} & {$[0.004]$} & {$[0.008]$} & {$[0.009]$} \\
Ramadan X Muslim & $-0.042^{* *}$ & $-0.040^{* *}$ & $-0.034^{* *}$ & $-0.035^{*}$ \\
& {$[0.005]$} & {$[0.006]$} & {$[0.013]$} & {$[0.014]$} \\
Observations & 233204 & 159700 & 233204 & 159700 \\
Adjusted $R^{2}$ & 0.720 & 0.708 & 0.392 & 0.363 \\
\hline \hline
\end{tabular}

Notes: Robust standard errors clustered by individual in parentheses. $+,{ }^{*}, * *$ denote significance at the $10 \%, 5 \%$ and $1 \%$ levels, respectively. Regressions include year fixed effects, individual fixed effects and a constant term. 
Appendix Table A.5: Estimates of Time in the UAE and Firm Tenure on Income and Remittances

\begin{tabular}{|c|c|c|c|c|}
\hline & \multicolumn{2}{|c|}{ Log Earnings } & \multicolumn{2}{|c|}{ Log Remittances } \\
\hline & $(1)$ & $(2)$ & $(3)$ & (4) \\
\hline \multirow[t]{2}{*}{ Time in UAE } & $0.030^{*}$ & $0.049^{*}$ & $-0.056^{* *}$ & -0.026 \\
\hline & {$[0.012]$} & {$[0.024]$} & {$[0.017]$} & {$[0.036]$} \\
\hline \multirow[t]{2}{*}{ Time in $\mathrm{UAE}^{2}$} & & -0.002 & & -0.004 \\
\hline & & {$[0.003]$} & & {$[0.004]$} \\
\hline \multirow[t]{2}{*}{ Tenure } & -0.014 & -0.032 & $-0.041^{*}$ & $-0.060+$ \\
\hline & {$[0.012]$} & {$[0.024]$} & {$[0.017]$} & {$[0.035]$} \\
\hline \multirow[t]{2}{*}{ Tenure $^{2}$} & & 0.002 & & 0.002 \\
\hline & & {$[0.003]$} & & {$[0.004]$} \\
\hline F-Test: Time \& $\operatorname{Time}^{2}$ (p-value) & & 0.012 & & 0.001 \\
\hline Observations & 543903 & 543903 & 543903 & 543903 \\
\hline Adjusted $\mathrm{R}^{2}$ & 0.719 & 0.719 & 0.400 & 0.400 \\
\hline
\end{tabular}

Notes: Robust standard errors clustered by individual in parentheses. $+,{ }^{*},{ }^{* *}$ denote significance at the $10 \%, 5 \%$ and $1 \%$ levels, respectively. Tenure refers to the number of months that they have been with the firm divided by 10 . Regressions include year indicators, month indicators, individual fixed effects and a constant term.

Appendix Table A.6: Relationship between Log Earnings and Log Remittances by Time in the UAE

\begin{tabular}{lcc}
\hline \hline & $(1)$ & $(2)$ \\
\hline Log Earnings & $0.324^{* *}$ & $0.323^{* *}$ \\
& {$[0.008]$} & {$[0.005]$} \\
Log Earnings $\times$ TimeinUAE & 0.000 & \\
& {$[0.003]$} & \\
Log Earnings $\times$ I(Time $>21$ Months) & & $0.003^{* *}$ \\
& & {$[0.001]$} \\
Observations & 543903 & 543903 \\
Adjusted $R^{2}$ & 0.421 & 0.421 \\
\hline \hline
\end{tabular}

Notes: Robust standard errors clustered by individual in parentheses. $+,{ }^{*}, * *$ denote significance at the $10 \%, 5 \%$ and $1 \%$ levels, respectively. Regressions include year-month indicators, individual fixed effects and a constant term. 
Appendix Figure A.1: Kernel Density of Log Earnings and Log Remittances

(a) Log Earnings

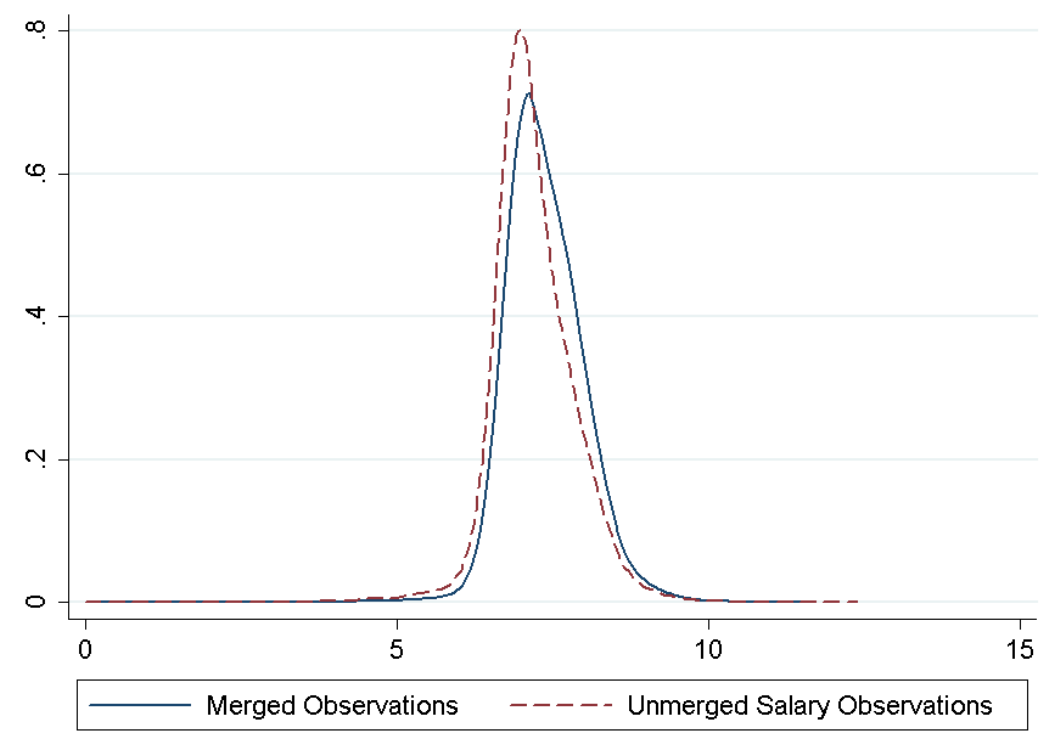

(b) Log Remittances

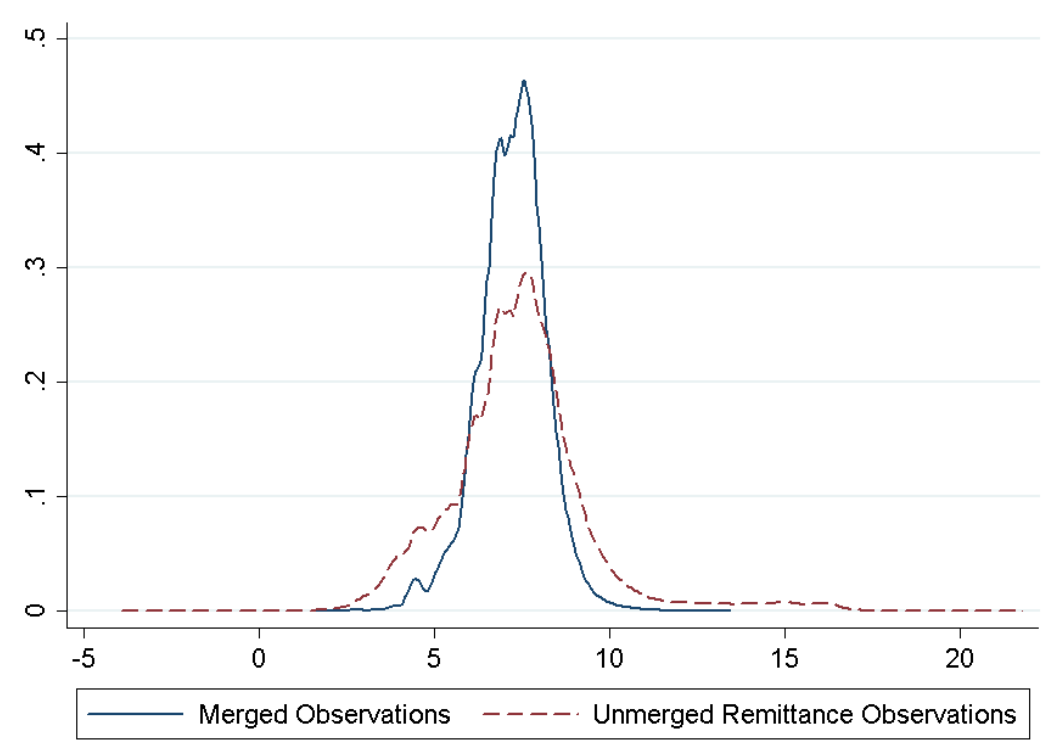


Appendix Figure A.2: Average Earnings and Remittances by Month

(a) Log Earnings

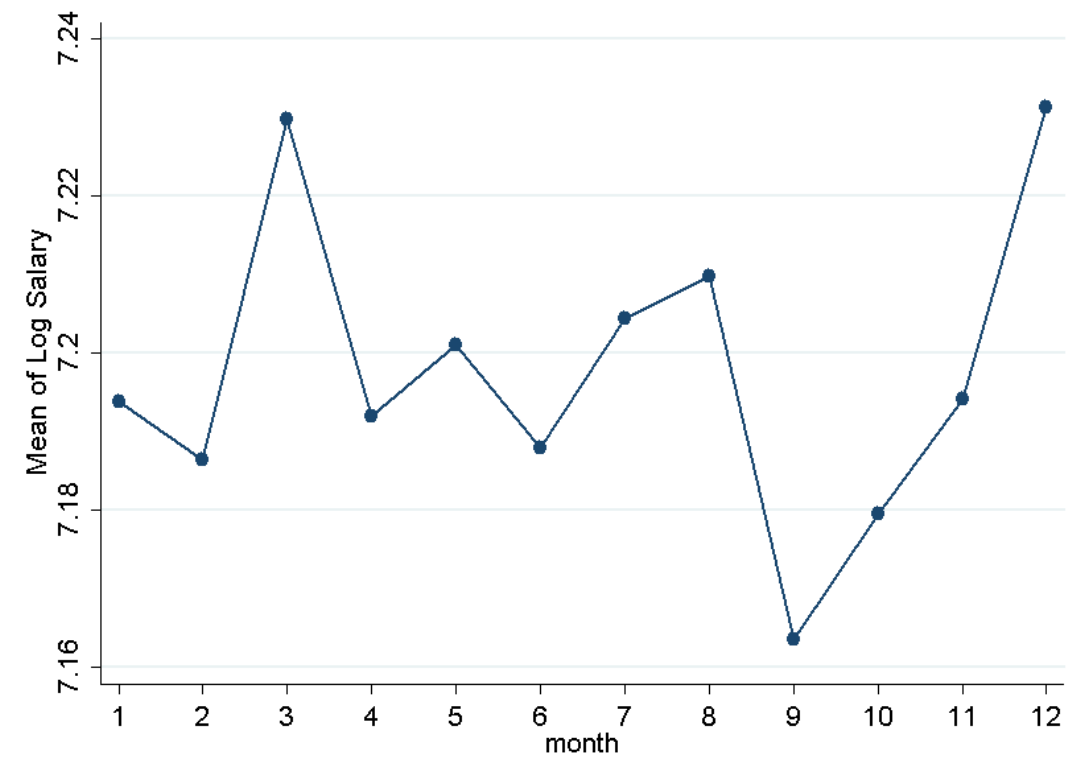

(b) Log Remittances

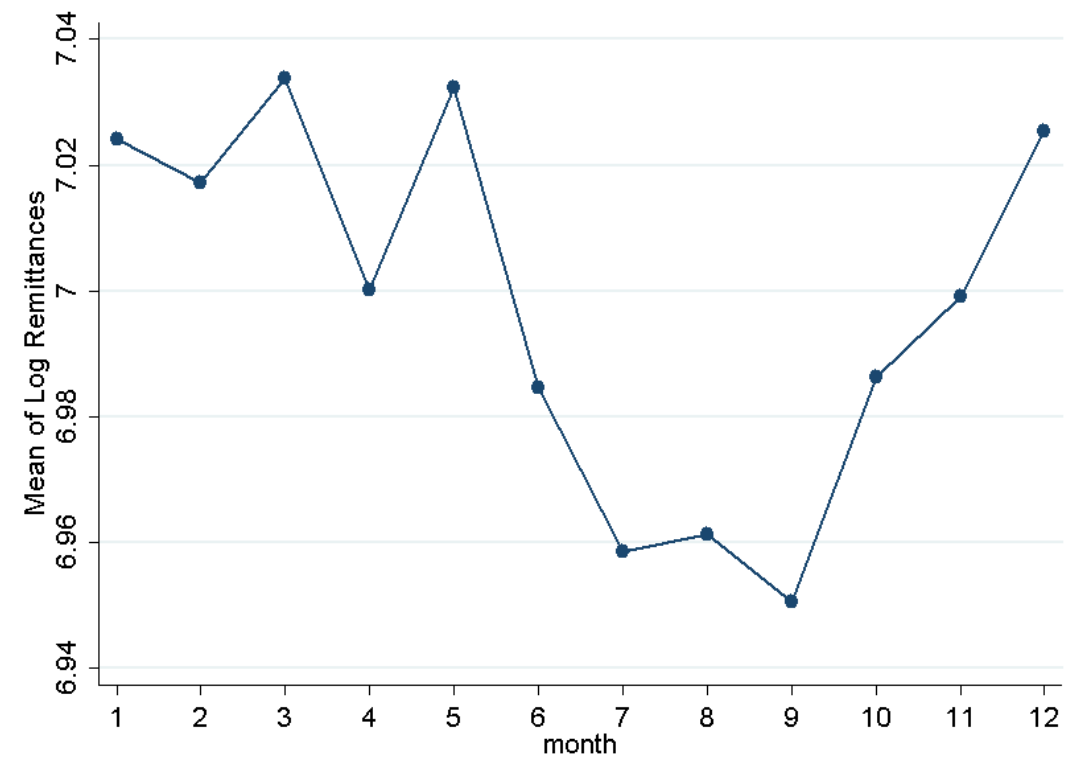


Appendix Figure A.3: Kernel Density of Log Earnings by Ramadan Months

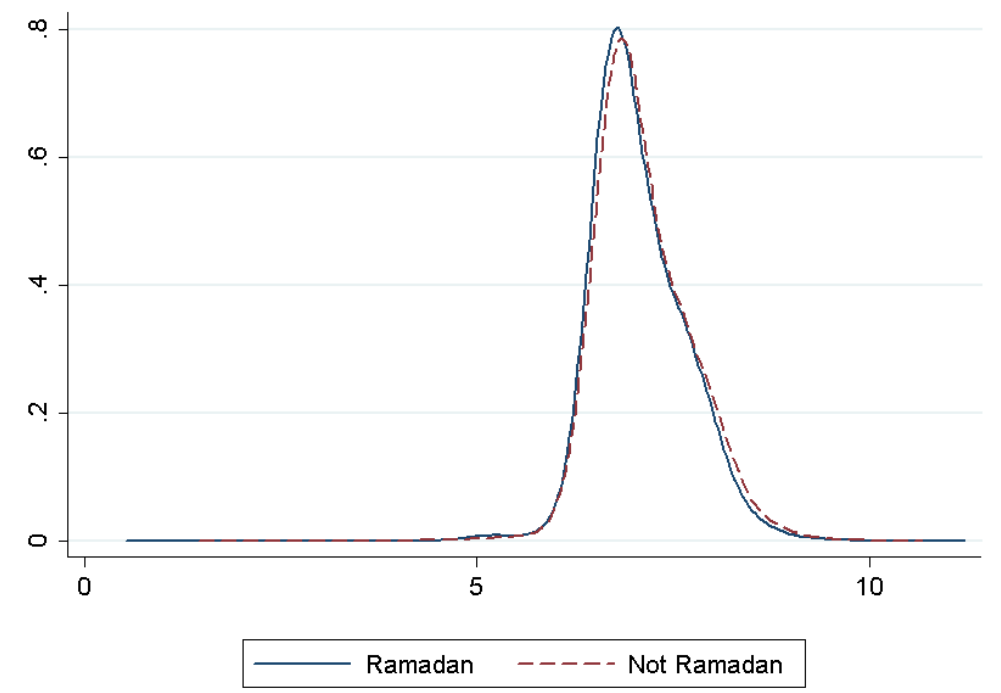

Appendix Figure A.4: Kernel Density of Firms' Share of Workers with Positive Changes over Time

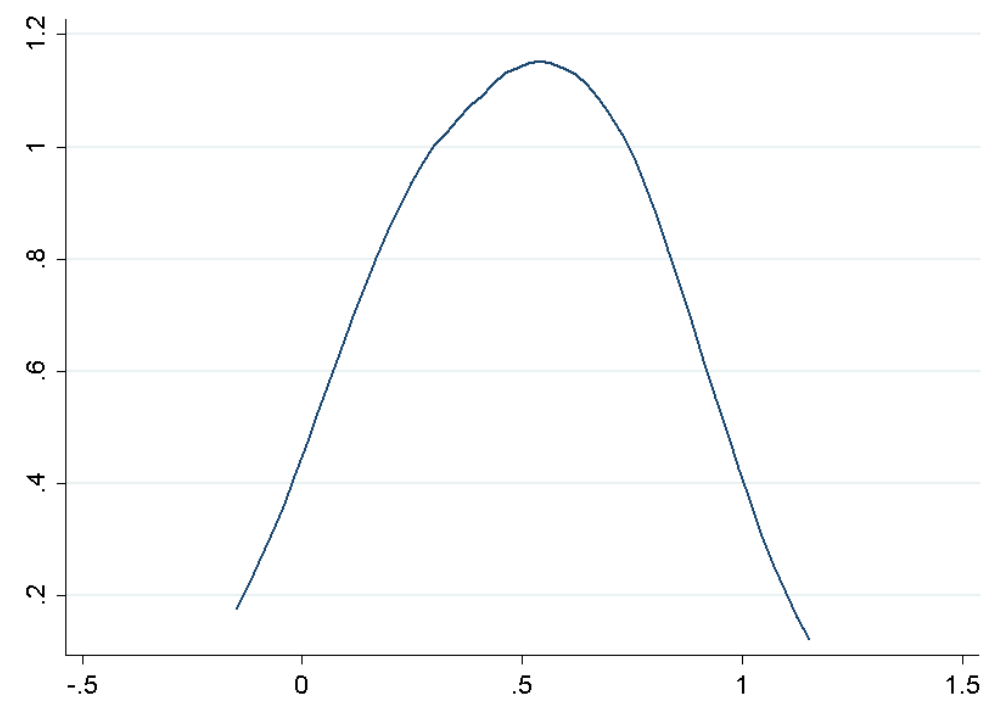

